\title{
Escherichia coli $\beta$-Lactamases: What Really Matters
}

\author{
Priyanka Bajaj, Nambram S. Singh and Jugsharan S. Virdi* \\ Microbial Pathogenicity Laboratory, Department of Microbiology, University of Delhi South Campus, New Delhi, India
}

Escherichia coli strains belonging to diverse pathotypes have increasingly been recognized as a major public health concern. The $\beta$-lactam antibiotics have been used successfully to treat infections caused by pathogenic E. coli. However, currently, the utility of $\beta$-lactams is being challenged severely by a large number of hydrolytic enzymes - the $\beta$-lactamases expressed by bacteria. The menace is further compounded by the highly flexible genome of $E$. coli, and propensity of resistance dissemination through horizontal gene transfer and clonal spread. Successful management of infections caused by such resistant strains requires an understanding of the diversity

OPEN ACCESS

Edited by:

David W. Graham

Newcastle University, UK

Reviewed by:

Ana Cláudia Coelho,

Universidade de Trás-os-Montes

e Alto Douro, Portugal

Alessandra Polissi,

Università degli Studi

di Milano-Bicocca, Italy

Sulagna Basu,

National Institute of Cholera

and Enteric Diseases, India

${ }^{*}$ Correspondence:

Jugsharan S. Virdi

virdi_dusc@rediffmail.com

Specialty section:

This article was submitted to Antimicrobials, Resistance

and Chemotherapy,

a section of the journal

Frontiers in Microbiology

Received: 07 January 2016 Accepted: 14 March 2016

Published: 30 March 2016

Citation: Bajaj P, Singh NS and Virdi JS (2016) Escherichia coli $\beta$-Lactamases: What Really Matters.

Front. Microbiol. 7:417. doi: 10.3389/fmicb.2016.00417 of $\beta$-lactamases, their unambiguous detection, and molecular mechanisms underlying their expression and spread with regard to the most relevant information about individual bacterial species. Thus, this review comprises first such effort in this direction for $E$. coli, a bacterial species known to be associated with production of diverse classes of $\beta$-lactamases. The review also highlights the role of commensal $E$. coli as a potential but under-estimated reservoir of $\beta$-lactamases-encoding genes.

Keywords: $\beta$-lactamase, commensal, detection, $E$. coli, genotypes, rapid diagnostics, resistance genes

\section{INTRODUCTION}

Since its discovery in 1885, the status of Escherichia coli has evolved truly. While the commensal strains for the most part have been shown to lack specialized virulence determinants and be beneficial to their host, pathogenic $E$. coli have been reported to cause a spectrum of diseases (Kaper et al., 2004; Baker, 2015). Among the intestinal pathogenic E. coli, the enterotoxigenic E. coli (ETEC) and the enteropathogenic E. coli (EPEC) have been recognized as the most common cause of bacterial gastroenteritis especially, in low income countries with poor sanitation conditions (Qadri et al., 2005; Croxen et al., 2013). In the developed countries, however, diarrhea caused by E. coli is usually observed as cases of traveler's diarrhea (caused by ETEC strains) or sporadic occurrences (Centers for Disease Control and Prevention, 2016). In these developed parts of the world, the enterohemmorhagic E. coli (EHEC) represent the most important group of intestinal pathogenic E. coli, and have been associated with severe morbidity and mortality (Riley et al., 1983; Majowicz et al., 2014). Distinct from the commensals and intestinal pathogens, the extraintestinal pathogenic E. coli (ExPEC) cause infections of the urinary tract, bloodstream, cerebrospinal fluid, respiratory tract, and peritoneum. The pathology in such infections may be observed as cholecystitis, bacteremia, cholangitis, urinary tract infection (UTI), or neonatal meningitis. Infections caused by the ExPEC strains have been widely reported in the community settings as well as hospitals and long-term care facilities thus, causing a pronounced burden on the medical and economic resources across the globe (Russo and Johnson, 2003; Riley, 2014; Poolman and Wacker, 2016). 
Different options have been suggested for treating the infections caused by diverse pathogenic E. coli. For instance, E. coli diarrhea is usually considered self-limiting or treated by maintaining adequate rehydration. However, in most instances especially cases of life threatening extraintestinal infections, antibiotics form the mainstay of treatment. In this regard, $\beta$-lactam antibiotics have long been used successfully (Paterson and Bonomo, 2005; Pfeifer et al., 2010). However, concomitant with their introduction during the early 1980s, $\beta$-lactamases conferring resistance to third generation cephalosporins were documented in several studies (Jacoby et al., 1988; Jarlier et al., 1988). These primarily included the extended-spectrum $\beta$-lactamases (ESBLs) observed either as the variants of TEM1, TEM-2, and SHV-1 (Philippon et al., 1989; Bradford, 2001), or the CTX-M enzymes (Bonnet, 2004). Additional resistance to cephamycins and carbapenems soon followed by the emergence of the AmpC $\beta$-lactamases (Philippon et al., 2002; Jacoby, 2009) and carbapenemases (Livermore, 2009; Kumarasamy et al., 2010; Nordmann et al., 2011a).

Extensive information is available on detection, distribution, classification and molecular characterization of $\beta$-lactamases (Bradford, 2001; Philippon et al., 2002; Queenan and Bush, 2007; Jacoby, 2009; Nordmann et al., 2011a). However, much of this information is being published from the perspective of the enzyme per se, i.e., ' $\beta$-lactamases', with much less attention to organism-specific details. A platform which succinctly provides such details for individual bacterial species having clinical relevance to humans is highly desirable. This would help the modern microbiologists and clinicians to develop targeted combat strategies and address better the public health concerns raised by antibiotic resistant pathogens. As a first effort of its kind in this direction, the present review focuses on what needs to be culled out from the vast knowledge on " $\beta$-lactamases mediating antibiotic resistance in E. coli" - what is more relevant today. In the latter part, this review also addresses the role of commensal $E$. coli as potential reservoir of $\beta$-lactamase-encoding genes.

\section{$\beta$-LACTAMASES OF CRITICAL CONCERN}

\section{CTX-M Type ESBLs}

Although, more than 150 different TEM- and SHV- type ESBLs are known (http://www.lahey.org/Studies/), the CTX-M enzymes have been recognized as the most prevalent among Enterobacteriaceae (Bush, 2010; Cantón et al., 2012; D’Andrea et al., 2013; Day et al., 2016). In fact, E. coli was the first species in which the CTX-M type ESBLs were reported as early as 1990 (Bauernfeind et al., 1990). Since then, the E. coli strains carrying CTX-M have been isolated from both nosocomial and community-acquired infections (Bonnet, 2004; Woodford et al., 2004; Smet et al., 2010). More recently, the CTX-M phenotype has also been reported in E. coli strains isolated from healthy humans, livestock, companion animals, food products, and sewage (Pallecchi et al., 2007; Ewers et al., 2012; Tacão et al., 2012; Zheng et al., 2012; Franz et al., 2015), indicating the large-scale of the reservoirs harboring and disseminating these ESBLs.

Such global dissemination of the CTX-M type ESBLs has primarily been attributed to the extremely mobilizable genetic

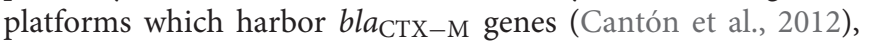
association of these platforms with E. coli genotypes showing clonal dissemination (Coque et al., 2008; Nicolas-Chanoine et al., 2008; Woodford et al., 2011), and frequent co-existence of bla $a_{\mathrm{CTX}-\mathrm{M}}$ with genes conferring resistance to other classes of antibiotics like fluoroquinolones and aminoglycosides leading to high rates of co-selection (Cantón and Ruiz-Garbajosa, 2011; Bajaj et al., 2015). Analysis of the genetic environments of bla $a_{\mathrm{CTX}-\mathrm{M}}$ genes has revealed that the promoter sequence present in the upstream region significantly affects gene expression as well as its dissemination (summarized in Table 1). The genetic elements downstream of the genes encoding CTX-M ESBLs, on the other hand, have been identified in most instances but very little has been established regarding their association with a specific type of $b l a_{\mathrm{CTX}-\mathrm{M}}$ or their role in gene selection and mobilization, if any.

In particular, the E. coli strains carrying CTX-M-14 and CTXM-15 ESBLs have been observed notably for their widespread dissemination (Bonnet, 2004; Coque et al., 2008; NicolasChanoine et al., 2008). These have also been reported to show differential demographic associations such that the strains producing CTX-M-15 ESBLs have been mainly isolated from patients related to the Indian subcontinent whereas, those producing the CTX-M-14 ESBLs have been isolated from patients related to China and the rest of the South East Asia (Hawkey and Jones, 2009; Freeman et al., 2012; Liao et al., 2015). The E. coli strains carrying CTX-M-14 or CTX-M-15 ESBL have also been observed for differential susceptibilities to fluoroquinolones and amoxicillin-clavulanic acid (Freeman et al., 2012). This infact, should be considered as an important observation because both these antimicrobials constitute important alternatives for the treatment of infections caused by $\beta$-lactamase-producing strains of E. coli.

Furthermore, it has been observed that unlike majority of CTX-Ms which exhibit better hydrolysis of cefotaxime (cefotaxime minimum inhibitory concentrations, MIC $\geq 64 \mu \mathrm{g} / \mathrm{ml}$ ) than ceftazidime (ceftazidime MIC 2$8 \mu \mathrm{g} / \mathrm{ml}$ ), CTX-M-15 possesses increased activity against both these antibiotic substrates (Poirel et al., 2001; Paterson and Bonomo, 2005). In most instances, the E. coli strains associated with the carriage of CTX-M-15 type ESBLs have been identified to belong to the international sequence type (ST) 131 (Coque et al., 2008; Nicolas-Chanoine et al., 2008; Peirano et al., 2014b); discussed in greater details with other major resistance-associated genotypes.

\section{AmpC $\beta$-Lactamases}

The AmpC $\beta$-lactamases comprise another important group of $\beta$-lactamases from $E$. coli which exhibit a hydrolytic profile similar to the ESBLs while having an additional hydrolytic activity toward cephamycins like cefoxitin and cefotetan. The inhibition of AmpCs is usually caused by cloxacillin and boronic acid, but not by the common $\beta$-lactamase inhibitors viz. clavulanic acid 
TABLE 1 | Details of the upstream regions associated with different bla ${ }_{\mathrm{CTX}-\mathrm{M}}$ genes.

\begin{tabular}{|c|c|c|}
\hline Upstream region & $b / a_{\mathrm{CTX}-\mathrm{M}}$ & Reference \\
\hline $\begin{array}{l}\text { ORF513, often associated with complex sul1-type } \\
\text { integron bearing a common region (CR1) }\end{array}$ & bla $a_{C T X-M-9}$ & $\begin{array}{l}\text { Sabaté et al., 2002; } \\
\text { García et al., 2005; } \\
\text { Novais et al., } 2006\end{array}$ \\
\hline Phage related invertase & bla $\mathrm{CTX}_{\mathrm{M}-10}$ & Oliver et al., 2005 \\
\hline ISEcp1 disrupted by IS50 & bla & Munday et al., 2004 \\
\hline
\end{tabular}

and tazobactam (Bradford, 2001; Jacoby, 2009; Thomson, 2010; Helmy and Wasfi, 2014).

In $E$. coli, regulation of $A m p C$ production by the chromosomal ampC gene is distinctly characterized by the lack of AmpR which constitutes a member of the LysR transcriptional regulator family (Honoré et al., 1986). Therefore, unlike most other members of the family Enterobacteriaceae, E. coli exhibits a non-inducible AmpC phenotype (Jaurin et al., 1981 ) and the wild-type strains constitutively produce low levels of AmpC enzyme. In most cases, hyperproduction is governed by mutations in the promoter/attenuator region that maps between -42 to +81 positions with respect to the $\operatorname{ampC}$ open reading frame (Caroff et al., 1999; Nelson and Elisha, 1999; Peter-Getzlaff et al., 2011; Haenni et al., 2014). In others, the chromosomal AmpC hyperproduction has been reported to be caused by the presence of $>1$ copy of the ampC gene, incorporation of a stronger promoter sequence as part of an insertion element, or acquisition of stronger promoter from other bacterial species (Jaurin et al., 1981; Jaurin and Normark, 1983). It is important to note that irrespective of the mechanism involved, all such strains are collectively known as 'derepressed mutants' (Hanson and Sanders, 1999).

Besides hyperperproduction of the chromosomally encoded enzyme, the presence of one or more plasmid-mediated ampC genes has often been observed as a common, rather more widespread mechanism of production of high levels of AmpC. Based on the sequence similarities, six families of plasmidmediated AmpC $\beta$-lactamases were described by Pérez-Pérez and Hanson (2002) as CIT, FOX, MOX, DHA, EBC, and ACC. Among the strains of E. coli, the most commonly recognized plasmid-mediated AmpC includes the CMY-2 type which belongs to the CIT family and shares homology with the chromosomally encoded AmpC from Citrobacter freundii (Sidjabat et al., 2009; Oteo et al., 2010; Helmy and Wasfi, 2014). Single nucleotide variants of bla $a_{\mathrm{CMY}-2}$ have recently been described and have been associated with extended-spectrum of activity and increased MICs of cefotaxime, ceftazidime, cefepime and aztreonam (Hentschke et al., 2011; Kotsakis et al., 2013). Another variant of CMY-2 namely, CMY-13 has been shown to be regulated by a functional AmpR and exhibit an inducible expression similar to the DHA enzymes but unlike the other CMY types (Miriagou et al., 2004). Although, naturally occurring variants have been described within other families of plasmid-mediated AmpC, the effects of mutations on enzyme activity were either not substantial or not studied much.

\section{Carbapenemases Including Metallo $\beta$-Lactamases}

Since, ESBL and AmpC producing E. coli strains are being frequently reported worldwide, carbapenems possibly represent the last alternative for effective treatment of life threatening infections (Thomson, 2010; Nordmann et al., 2011a; Poirel et al., 2016). One of the most common mechanisms of carbapenem resistance is mediated by the production of carbapenemases which represent $\beta$-lactamases of the most diverse hydrolytic potential (Queenan and Bush, 2007).

Detailed biochemical and epidemiological characteristics of each of the carbapenemase classes viz. A, B, and D have been described in depth in the reviews by Queenan and Bush (2007) and Nordmann et al. (2011a). Herein, it is important to note that the most widespread and clinically significant representatives of each class namely Klebsiella pneumoniae carbapenemases (KPC, class A); metallo- $\beta$-lactamases (MBLs, class B); and oxacillinhydrolyzing metallo- $\beta$-lactamases (OXA, class $\mathrm{D}$ ) have frequently been reported in different E. coli strains (Urban et al., 2008; Kumarasamy et al., 2010; Beyrouthy et al., 2013). Despite this, it is also noteworthy that in most instances the production of KPC and OXA carbapenemases as well as MBLs of the IMP and VIM type has been associated with strains of $K$. pneumoniae and Acinitobacter baumannii (Afzal-Shah et al., 2001; Nordmann et al., 2009, 2011a; Pournaras et al., 2010; Bartolini et al., 2014).

Strains of E. coli, nevertheless have been notorious for the production of a metallo- $\beta$-lactamase known as the New Delhi metallo- $\beta$-lactamase (NDM-1) (Kumarasamy et al., 2010; Nordmann et al., 2011b). High prevalence of the E. coli carrying NDM-1 has been observed in the Indian subcontinent where the organism per se represents one of the most common causes of diarrheal and other community-acquired diseases. The resultant high possibility of environmental contamination and spread of the bla $a_{\mathrm{NDM}-1}$ gene has been supported by the transcontinental spread of NDM-1 producing strains from India and Pakistan to the UK (Kumarasamy et al., 2010), Australia (Poirel et al., 2010), and US (Peirano et al., 2011). Frequent 
co-existence of the bla $a_{\mathrm{NDM}-1}$ gene on plasmids carrying other resistance genetic elements (Moellering, 2010; Nordmann et al., 2011b) is also suggested to contribute to the selection and worldwide dissemination of multi-drug resistance phenotype, making E. coli strains carrying $b l a_{\mathrm{NDM}-1}$ a global public health concern.

\section{Other Notable $\beta$-Lactamases}

The category primarily includes inhibitor-resistant and complex mutant $\beta$-lactamase variants of the TEM and SHV types. The strains of $E$. coli have been most commonly associated with these variants (Robin et al., 2011), which have been seen to evolve by both in vitro and in vivo antibiotic selective pressures (Barlow and Hall, 2002; Jacquier et al., 2013). While several mechanisms of resistance to $\beta$-lactam- $\beta$-lactamase inhibitor combinations have been suggested in $E$. coli, production of inhibitor-resistant TEMs (IRTs) or OXA-1 enzymes has been reported to predominate as the mechanism conferring resistance to amoxicillin-clavulanic acid - a widely used antibiotic for the treatment of E. coli infections. Such amoxicillin-clavulanic acid resistant strains of E. coli have been observed to be more clonal, but with lesser content of virulence genes than the susceptible strains (Oteo et al., 2014). Similar, albeit not yet completely characterized mechanisms have been suggested to provide resistance to another commonly used antibiotic-inhibitor combination viz. ampicillinsulbactam (Cantón et al., 2008).

Besides the IRTs, an S130G inhibitor-resistant mutation associated with the SHV enzyme in the E. coli clinical isolate was reported by Prinarakis et al. (1997) as early as. Since then, however, the E. coli strains carrying inhibitorresistant SHV have not been very frequent in the clinics. In 2000, M. G. Page described another mutation at Y105 to confer resistance to clavulanic acid. However, no clinical strain harboring this mutation has been reported so far. The main reason behind the absence of Y105 mutation in clinical strains has been suggested as the significance of position 105 in both substrate and inhibitor interaction (Li et al., 2012). Thus, inhibitors targeting residue 105 may be protected because inhibitor-resistant mutation also tends to decrease the overall efficiency of enzyme catalysis. This position has therefore, been suggested to be an important target for the design of newer inhibitors of broad-spectrum $\beta$-lactamases. Other positions in the SHV enzymes viz. N276, K234, and R244 have also been shown to confer reduced susceptibility to $\beta$-lactam-clavulanic acid combinations (Thomson et al., 2007; Manageiro et al., 2010; Winkler et al., 2015). The position R244, however, has interestingly been shown to have differential effects on the different $\beta$-lactamase inhibitors - clavulanic acid and sulbactam (Thomson et al., 2007).

It is noteworthy that the CTX-M type ESBL variants showing reduced susceptibilities to $\beta$-lactam- $\beta$-lactamase inhibitor combinations have not yet been observed. This could most likely be attributed to the limited exposure of mutant strains to such combinations or rather the recommended use of carbapenems as the treatment of choice (Pitout, 2010; Ortega et al., 2012); or limitations in detection procedures leading to confusions with other mechanisms such as the expression of
IRTs or complex mutant TEMs (CMTs) (Ripoll et al., 2014). Nevertheless, an increase in the use of antibiotic-inhibitor combinations in the clinical settings is quite well-expected to result in the emergence and dissemination of strains carrying the inhibitor-resistant CTX-Ms. Infact, experiments using a collection of hypermutagenic E. coli strain GB20 carrying different $b a_{\mathrm{CTX}-\mathrm{M}}$ genes have shown that such possibilities may be higher for the variants belonging to the CTX-M-1 group (Ripoll et al., 2011). Not to forget that the latter is already associated with the most widespread variants of the CMX-M ESBLs.

\section{DETECTION OF $\beta$-LACTAMASES}

\section{Phenotypic Detection}

\section{(a) Conventional Laboratory Methodologies}

The standardized methodologies for phenotypic antibiotic susceptibility testing and breakpoints for interpretation of results are available primarily from Clinical and Laboratories Standards Institute (CLSI) and European Committee on Antimicrobial Susceptibility Testing (EUCAST). Although, both suggest a similar basic protocol for preliminary testing, variations are often observed in the suggested breakpoints (Clinical and Laboratory Standards Institute [CLSI], 2014a,b,c Document M02-A11, M07-A9, M100-24; European Committee on Antimicrobial Susceptibility Testing [EUCAST], 2014 Version 4.0).

For detection of ESBL-producing E. coli, both CLSI and EUCAST recommend the use of cefotaxime as well as ceftazidime as indicator cephalosporins, and employ E. coli ATCC 25922 as the wild type quality control strain. Besides this, the ESBL Etest available from bioMérieux (Marcy l'Etoile, France) or Cambridge Diagnostics Services Ltd (Cambridge, UK) is often used in many clinical microbiology laboratories.

Unlike ESBLs, no standardized guidelines are available from CLSI for the detection of AmpC producing E. coli. Nevertheless, in routine microbiology, a high MIC of cefoxitin $(>8 \mathrm{mg} / \mathrm{L})$ is considered to be an indicator of AmpC phenotype. Further confirmation by one or more methods is usually required and employs AmpC inhibitors like boronic acid derivatives or cloxacillin in a test format similar to the CLSI ESBL phenotypic confirmatory test (Brenwald et al., 2005; Tan et al., 2008; Tenover et al., 2009). Overall, the disk-based methods have been shown to be more sensitive and specific than the agar dilution methods and cefoxitin-cloxacillin combination disk method has been shown to provide the most accurate results (Tan et al., 2008).

Thus, like other Enterobacteraceae, it is easy to detect the $E$. coli strains which produce AmpC $\beta$-lactamases. However, differentiation of the chromosomal AmpC hyperproduction from the plasmid-mediated enzymes is not possible solely on the basis of phenotypic tests. Moreover, detection of inducible DHAlike AmpC $\beta$-lactamases requires the use of an additional test known as the 'disk approximation assay' wherein, an inducer and reporter antibiotic substrate are used and results are considered positive if the inhibition zone reduces by $\geq 2 \mathrm{~mm}$ 
on the induced side of the reporter disk (Dunne and Hardin, 2005).

Similar to the detection of AmpC $\beta$-lactamases, the guidelines for initial screening of carbapenemase-producing E. coli may be applied to other members of Enterobacteriaceae as well. Preliminary detection of carpapenemase production involves MIC breakpoints for imipenem, ertapenem and meropenem (Clinical and Laboratory Standards Institute [CLSI], 2014c, Document M100-24; European Committee on Antimicrobial Susceptibility Testing [EUCAST], 2014 Version 4.0). For confirmation of carbapenemase production, CLSI recommends the Modified Hodge test (MHT) (M100-S20). However, despite being a useful method for initial detection of carbapenemase production (especially, the KPC type), MHT has gained limited popularity because of the long time consumption, $c a$. 24-48 h; low specificity, in case of high ESBL and/or AmpC activity; and low sensitivity, mainly for the NDM-1 producers (Miriagou et al., 2010; Lutgring and Limbago, 2016).

For better detection of the diverse carbapenemase classes including, metallo- $\beta$-lactamases, different inhibitor-based methods have been suggested which often employ the algorithm proposed by Giske et al. (2011). These methods also allow differentiation of carbapenem resistance caused by the production of carbapenemases per se from that caused by a high AmpC activity, usually by incorporating cloxacillin in the plating medium (Giske et al., 2011; Nordmann et al., 2012a). However, lack of suitable inhibitors limits the application of inhibitor-based methods in the detection of OXA-48-like enzymes where, a high MIC of temocillin $(>32 \mathrm{mg} / \mathrm{L}$ ) or resistance to piperacillin-tazobactam with no AmpC production has been shown to provide good results (Glupczynski et al., 2012). Besides these, detection of NDM-1 producing E. coli can be performed by using Etest MBL strips (AB bioMérieux, Solna, Sweden) consisting of a gradient of imipenem concentrations on one side and imipenem with ethylenediaminetetraacetic acid (EDTA) on the other; or combined disk test using imipenem disks with and without EDTA (Franklin et al., 2006).

\section{(b) Automated and Rapid Detection}

The commercial methods available for rapid detection of ESBL producers include - VITEK 2 ESBL test (bioMérieux, Marcy l'Etoile, France), Phoenix ESBL test (Becton Dickinson, Sparks, MD, USA), and Microscan WalkAway-96 System (Dade Behring, West Sacramento, CA, USA). Besides these, MALDI-TOF MS or the recently described chromogenic and $\beta$ LACTA tests have been suggested for rapid detection of $E$. coli strains producing ESBLs (Compain et al., 2015; Dortet et al., 2015).

Despite an overall similar performance of these automated systems, the results should be examined critically due to the possibility of upto $5 \%$ error based on antibiotic-organism combination and instrument handling. In case of ESBLproducing E. coli strains, a comparative analysis of the automated methods, double-disk synergy test, and combination disk methods has shown combination disk method as the best choice followed by ESBL Etest (Wiegand et al., 2007). However, it is important to consider that the accuracy of combination disk method is subject to inaccuracy when the strain under consideration co-produces AmpC $\beta$-lactamases (Drieux et al., 2008; Munier et al., 2010). Therefore, it is recommended that confirmation of ESBL production should be done by one or more additional tests. Some of these are suggested by the EUCAST guidelines for detection of resistance mechanisms and specific resistances of clinical and/or epidemiological importance (December 2012), and include the use of cefepime as an indicator cephalosporin in either of the test formats or the use of cloxacillin to inhibit AmpC $\beta$-lactamase activity (Drieux et al., 2008; Nourrisson et al., 2015).

The most commonly available commercial methods for rapid detection of AmpC $\beta$-lactamases include the AmpC Etest (bioMérieux, Marcy l'Etoile, France) and the D69C AmpC Detection Disc Set (Mast Group Ltd, UK). The D69C AmpC Detection Disc Set has been shown as a promising candidate for the detection of both, plasmid-borne as well as chromosomal AmpC, irrespective of their constitutive, inducible or derepressed nature (Halstead et al., 2012). More recently, Hart et al. (2015) have shown the detection of CMY-2 type AmpC $\beta$-lactamases among others in E. coli strains using MALDI-TOF MS analysis following in solution trypsin digestion of periplasmic proteins and nano-LC based separation.

Rapid methods to detect carbapenemases includes the Carba NP test (Nordmann et al., 2012b) or MALDI-TOF analysis of carbapenem hydrolysis (Hrabák et al., 2012; Lasserre et al., 2015). Furthermore, screening for carbapenemase producing E. coli strains among carriers can be performed by directly using stools or rectal swabs, or by following an overnight enrichment step in broth medium containing one of the carbapenems (i.e., imipenem $-0.5-1 \mathrm{mg} / \mathrm{L}$ or ertapenem $-0.5 \mathrm{mg} / \mathrm{L}$ ) (Adler et al., 2011). In either case, different selective media may be employed with varying sensitivity and specificity. The most popular ones includes ChromID ESBL (bioMérieux, La Balme-les-Grottes, France) and CHROMagar KPC (CHROMagar Company, Paris, France). ChromID ESBL has been shown to provide high sensitivity but, it is often limiting in specificity especially, because of ESBL producers. CHROMagar KPC, on the other hand, has been shown to be more specific for carbapenemase producers but, exhibits lower sensitivity (Carrër et al., 2010). More recently, another medium viz. chromID CARBA (bioMérieux) has been shown to be an accurate method for detection of Enterobacterial strains which produce carbapenemases of KPC or NDM-1 types (Vrioni et al., 2012).

\section{Detection of $\beta$-Lactamase Encoding Genes}

\section{(a) PCR and Sequencing}

Despite the availability of various phenotypic methods, molecular biology techniques (especially, PCR and sequencing) serve as the gold standard for detection, identification and differentiation of different $\beta$-lactamases (Bradford, 2001). Molecular methods have also been successfully applied for the detection and analysis of resistance which is often associated with low level of $\beta$-lactamase expression (e.g., that caused by the OXA-48 carbapenemases), and for the identification of the exact mechanism of resistance (e.g., differentiation of carbapenem resistance caused by a high 
ESBL/AmpC activity coupled with porin mutation from that caused by the production of carbapenemases per se) (Gazin et al., 2012). Further improvements in the speed, sensitivity, and specificity have been achieved by the establishment of multiplex and real time PCR assays (Pérez-Pérez and Hanson, 2002; Birkett et al., 2007; Brolund et al., 2010; Poirel et al., 2011; Deccache et al., 2015). For instance, a multiplex PCR has been successfully applied for the detection of different families of plasmid-mediated AmpC $\beta$-lactamases, and their differentiation from the chromosomally encoded enzyme (Pérez-Pérez and Hanson, 2002). Similarly, a real-time multiplex PCR has recently been proposed and evaluated for the detection of genes encoding different carbapenemases among Gram-negative bacteria (van der Zee et al., 2014).

Sequencing of the PCR amplicons helps not only in the identification of genes but, also in the detection of newer genetic variants within a particular $\beta$-lactamase class which often differ only by a single nucleotide. The technique is therefore important for recognition of nucleotide positions significantly associated with enzyme activity, determination of the epidemiology of resistance genetic elements, and tracing the emergence and dissemination of newer variants. Thus, it has been observed that bla $a_{\mathrm{CTX}-\mathrm{M}-15}$ and $b l a_{\mathrm{CMY}-2}$, respectively, constitute globally the most disseminated genes for ESBL and plasmid-mediated AmpC produced by the E. coli strains (Nicolas-Chanoine et al., 2008; Oteo et al., 2010; Cantón et al., 2012; Helmy and Wasfi, 2014).

\section{(b) High-Throughput Analyses}

For high-throughput screening, different DNA microarrays and enzyme-linked immunosorbent assays (ELISA) have been developed. However, DNA microarrays have overtaken considerably as the method of choice and various advancements have been achieved over the recent years. The leading commercial DNA microarrays comprise the Check-Points assays (CheckPoints Health, Wageningen, The Netherlands) and the Identibac AMR-ve assays (Alere GmbH, Cologne, Germany). While both possess a similar turnaround time and classify the CTX-M type ESBLs further into their respective groups, the latter exhibits lower specificity and does not differentiate between the genes encoding narrow-spectrum $\beta$-lactamases and ESBLs (Gazin et al., 2012).

Given the diversity of $\beta$-lactamase encoding genes in E. coli, the latest of the Check-Points assays called the 'Check-MDR CT103 array' appears as a promising platform for rapid screening as it has been shown to exhibit $100 \%$ sensitivity and specificity of detection for the major gene-families encoding ESBLs (bla $a_{\mathrm{TEM}}, b l a_{\mathrm{SHV}}$, and bla $\left.a_{\mathrm{CTX}-\mathrm{M}}\right)$, plasmid-mediated AmpCs (bla $a_{\mathrm{CMY} / \mathrm{MOX}}, b l a_{\mathrm{DHA}}, b l a_{\mathrm{FOX}}, b l a_{\mathrm{ACC}}$, and $\left.b l a_{\mathrm{ACT} / \mathrm{MIR}}\right)$, and carbapenemases (bla $a_{\mathrm{KPC}}, b l a_{\mathrm{NDM}}, b l a_{\mathrm{VIM}}$, and $b l a_{\mathrm{IMP}}$ ). Additionally, the sensitivity and specificity for bla $a_{\mathrm{OXA}}-48$ were 95 and 100\%, respectively, (Cuzon et al., 2012).

Although, PCR and microarray based methodologies have been successfully applied in the detection and analysis of target genes encoding antibiotic resistance, these may not be sufficient to enable the discovery of rare or novel mechanisms of resistance. Whole genome sequencing has been increasingly advocated as a highly sensitive and specific approach in this regard. It has been shown to be especially useful for organisms having a complex pattern of antibiotic resistance; a classic example of which may be represented by E. coli. Several bioinformatics tools and databases (like ResFinder, ARG-ANNOT along with ClustalW, BLASTn, and/or BLASTx) have been developed to analyze the data obtained by whole genome sequencing and extract the antibiotic resistance genotypes including chromosomal mutations associated with resistance (Stoesser et al., 2013; Zankari et al., 2013). With appropriate cost reduction and methodological refinements whole genome sequencing seems sure to take over as a method of choice for resistance prediction in the near future.

\section{RESISTANCE, GENOTYPES, AND GLOBAL DISSEMINATION}

Several recent studies have described that the nature of antibiotic resistance in $E$. coli is often associated with the strains' genotype. The most predominant of the multidrug resistant (MDR) genotypes has been observed as the sequence type 131 (ST131) which belongs to phylogroup B2 and harbors extra-intestinal pathogenic strains mostly associated with urinary tract and bloodstream infections (Johnson et al., 2010; Courpon-Claudinon et al., 2011; Peirano et al., 2011; Rogers et al., 2011). The strains belonging to ST131 have been reported to carry several virulence genes which encode the aerobactin receptor (iutA), catecholate sidephore receptor (iroN), invasion of brain endothelium (ibeA), pathogenicity island marker $(\operatorname{malX})$, secreted autotransporter toxin (sat), uropathogenic-specific protein (usp), and fimH adhesin of type 1 fimbriae (Rogers et al., 2011; Blanco et al., 2013).

The most characteristic feature of the E. coli ST131 isolates vis$\grave{a}$-vis $\beta$-lactamase mediated antibiotic resistance has been their association with the pandemic spread of resistance mediated by the CTX-M-15 type ESBL (Coque et al., 2008; NicolasChanoine et al., 2008). This spread has been driven primarily by the strains belonging to a well defined clade within the subclone $H 30$ which has been designated as H30-Rx owing to its broader resistance profile (Price et al., 2013; Peirano et al., 2014b). The major vehicles for pandemic spread of CTXM-15 ESBL by E. coli strains belonging to ST131 have been recognized as plasmids especially, of the incompatibility groups IncF (e.g., pEK516, pEK499, pGUE-NDM, pC15-1a, pJJ1886-5, pEC_B24, pEC_L46, pEC_L8, pJIE186-2). Besides IncF, other plasmid incompatibility groups like IncK, IncX, and IncI have also been observed frequently in both ST131 and non-ST131 E. coli strains carrying CTX-M-15 ESBLs (Carattoli, 2013; Phan et al., 2015).

The ST131 strains have also been significantly associated with other CTX-M types as well as resistance to carbapenems, and other antibiotic classes like fluoroquinolones, trimethoprimsulfamethoxazole, and aminolglycosides (Oteo et al., 2009; Peirano et al., 2011, 2014b; Rogers et al., 2011; Morris et al., 2012). However, their association with plasmid-mediated AmpC has 
been less-well established. On the contrary, the spread of AmpCmediated antibiotic resistance (especially, the most widespread CMY-2 type) has been shown to be driven primarily by the strains belonging to phylogroup $\mathrm{D}$, and has been mostly associated with ST38 and ST448 (Sidjabat et al., 2009; Naseer et al., 2010; Oteo et al., 2010; Matsumura et al., 2013). Nevertheless, acquisition and spread of plasmid-mediated ampC genes by ST131, even to a lesser extent poses a serious public health concern for near future because the clone enjoys a global distribution and has successfully driven the dissemination of bla $a_{\mathrm{CTX}-\mathrm{M}-15}$ worldwide.

Apart from the AmpC $\beta$-lactamases, contribution of E. coli strains from phylogroup D in the spread of genes encoding CTX$M$ type ESBLs has also been noteworthy (Coque et al., 2008; van der Bij et al., 2011; Hansen et al., 2014). In this regard, ST405 has been observed as the most predominant genotype which stands second only to the ST131 clones from phylogroup B2 (Coque et al., 2008). This sequence type has primarily been associated with the large scale dissemination of CTXM-15 and CTX-M-9 group of ESBLs (Naseer and Sundsfjord, 2011). Other sequence types reported in association with CTX$M$ mediated antibiotic resistance include ST59, ST393, ST1395, and ST354 (CTX-M-14), ST38 (CTX-M-9), and ST648 (CTXM-15) (Mora et al., 2011; van der Bij et al., 2011). More recently, the globally distributed multidrug resistant genotypes (especially, ST69 and ST393/O15:K52:H1) which have chiefly been known for resistance to antibiotic classes like trimethoprimsulfamethoxazole have also been shown to be associated with resistance caused by the CTX-M type ESBLs (Johnson et al., 2009; Ewers et al., 2012; Izdebski et al., 2013; Hansen et al., 2014).

Thus, a major proportion of E. coli strains expressing ESBLs and plasmid-mediated AmpCs have been reported from the phylogroups (i.e., B2 and D) which have also been associated with higher virulence. Occasionally, however, similar resistance is also being reported from the sequence types belonging to phylogroups A and B1 (Oteo et al., 2009, 2010; Valverde et al., 2009). For instance, in a recent study, the predominant CTXM-15-producing E. coli in the fecal carriage of travelers and immigrants were reported to belong to phylogroup A (ST10) (Valverde et al., 2015). Besides this, ST410 and ST224 from phylogroup $\mathrm{A}$ and $\mathrm{B} 1$, respectively, have also been associated with E. coli strains producing CTX-M-15 ESBL (López-Cerero et al., 2011; Mshana et al., 2011; Silva et al., 2016). Corvec et al. (2007) have also shown the existence of a significantly high association of hyperproduction of the chromosomally encoded AmpC with E. coli strains belonging to phylogroup A. However, despite these reports, the contribution of phylogroups A or B1 in the global epidemiology of $\beta$-lactamase mediated antibiotic resistance remains to be established more clearly because none of the sequence types reported so far have been shown to play a role in the worldwide dissemination of either ESBLs or AmpCs.

Last but not the least, relatively lesser information is available regarding genotypic or sequence type associations of carbapenemase-mediated resistance in E. coli. Some of the studies, as described above, have indicated the role of ST131 in the clonal spread of carbapenemases (Peirano et al., 2011, 2014a; Morris et al., 2012). Meanwhile, others have highlighted the importance and probably a greater role played by ST101 (phylogroup B1) and ST405 (phylogroup D) especially, in conjunction with the NDM-1 type enzymes (Mushtaq et al., 2011; Pfeifer et al., 2011).

\section{$\beta$-LACTAMASES AND THE COMMENSAL E. coli}

For better management of emergence and dispersal of resistance, complete analysis of the abundance, diversity, and dissemination of resistance genes in bacteria including commensals is required. One of the most significant efforts in this regard has been made by the Alliance for the Prudent Use of Antibiotics (APUA). Through its Reservoirs of Antibiotic Resistance (ROAR) project, APUA aims to encourage research for determining antibiotic resistance in commensals. It also works to provide a comprehensive database for further analyses like prediction of the rates of resistance development in pathogens by evaluating the frequency of resistance genes in commensals.

Through several such individual and collaborative efforts, it has been acknowledged that the association of commensal E. coli with genes imparting antibiotic resistance constitutes a serious public health concern especially, with respect to resistance dissemination through community settings (Valverde et al., 2008; Machado et al., 2013). Despite being a minor proportion of microbiota colonizing the gastrointestinal tract of healthy individuals, the role of commensal $E$. coli as a reservoir of genes encoding $\beta$-lactamases has been acknowledged across the globe (Table 2). Among these, a large number of studies have reported a high prevalence of CTX-M type ESBLs in the strains isolated from healthy adults and children (Nys et al., 2004; Pallecchi et al., 2007; Woerther et al., 2013; Nakayama et al., 2015). A number of studies have also demonstrated a likewise prevalence in food and companion animals (Ben Sallem et al., 2012; Tian et al., 2012; Zheng et al., 2012).

Some of these studies have also indicated that animals might be responsible for the transfer of ESBL-producing bacteria and/or ESBL-encoding genes to humans, either through contact or via food chain (Jensen et al., 2006; Ewers et al., 2012). The indiscriminate use of antibiotics in the food and farming industry has therefore, been considered as one of the most significant risk factors responsible for high prevalence of ESBL producing E. coli among healthy subjects (Bailar and Travers, 2002; Larson, 2007). Antibiotic abuse related to consumption without prescription, and exposures related to family/community/foreign travel have been observed as other notable factors (RodríguezBaño et al., 2008; Tängdén et al., 2010; Luvsansharav et al., 2011).

Besides ESBLs, these factors have also contributed to the increased occurrence of AmpC $\beta$-lactamases in strains isolated from healthy humans and animals (Kaneko et al., 2006; Hammerum et al., 2011; Ben Sallem et al., 2012; Ewers et al., 2012). Occurrence of carbapenemase-producing 
TABLE 2 | World-wide occurrence of $\beta$-lactamase genes in commensal E. coli.

\begin{tabular}{|c|c|c|}
\hline $\begin{array}{l}\text { Countries reported } \\
\text { from }\end{array}$ & $\begin{array}{l}\beta \text {-lactamase genes } \\
\text { identified }\end{array}$ & Reference \\
\hline $\begin{array}{l}\text { Kenya, Mexico, Peru, } \\
\text { Philippines, Curacao, } \\
\text { Venezuela, Ghana, } \\
\text { Zimbabwe }\end{array}$ & ND & Nys et al., 2004 \\
\hline Latin America & blasHV,CTX-M & Pallecchi et al., 2007 \\
\hline Japan & bla $\mathrm{CMY}$ & Kaneko et al., 2006 \\
\hline USA & blaTEM, cTX-м & Sommer et al., 2009 \\
\hline Sweden & blaTEM, SHV, CTX-M & Tängdén et al., 2010 \\
\hline Australia & blaTEM & Bailey et al., 2010 \\
\hline China & $\begin{array}{l}\text { blaTEM, SHV, CTX-M, } \\
\text { CMY,KPC }\end{array}$ & Tian et al., 2012 \\
\hline China & blactX-M & Zheng et al., 2012 \\
\hline Tunis & blaтем, стх-M, CMY & Ben Sallem et al., 2012 \\
\hline Thailand & blactX-M & $\begin{array}{l}\text { Luvsansharav et al., } \\
2012\end{array}$ \\
\hline Switzerland & blaTEM, стX-м & Geser et al., 2012 \\
\hline Portugal & bla $\mathrm{TEM}_{\mathrm{M}}, \mathrm{cTX}-\mathrm{M}$ & Machado et al., 2013 \\
\hline Netherlands & $\begin{array}{l}\text { blaTEM, SHV, CTX-M, } \\
\text { CMY }\end{array}$ & Hordijk et al., 2013 \\
\hline India & $\begin{array}{l}\text { blaTEM, SHV, CTX-M, } \\
\text { CMY }\end{array}$ & Kothari et al., 2013 \\
\hline India & bla $\mathrm{CTX}-\mathrm{M}$ & Dureja et al., 2014 \\
\hline Germany & blatEM, SHV, CTX-M & Valenza et al., 2014 \\
\hline China & blaTEM, OXA & Li et al., 2014 \\
\hline Nigeria & blactX-M & Fortinia et al., 2015 \\
\hline USA & bla ${ }_{\mathrm{CTX}-\mathrm{M}, \mathrm{CMY}}$ & Davis et al., 2015 \\
\hline Vietnam & blactx-м & Bui et al., 2015 \\
\hline
\end{tabular}

ND: Not Determined.

E. coli in the community, however, has been reported in only a few studies. Furthermore, their acquisition by healthy humans has been associated chiefly with travel to the countries endemic in this regard (Tian et al., 2012; Ruppé et al., 2014)

Overall, more studies are required to assess the contribution of commensal E. coli strains in the epidemiology of genes encoding $\beta$-lactamases, and to understand the mechanisms by which these resistance genes are silently fed to the pathogenic strains.

\section{OTHER IMPORTANT CONSIDERATIONS}

Owing to the basic biology of the organism, the menace of ' $\beta$-lactamase mediated antibiotic resistance in $E$. coli' represents a concern which needs special attention. The genome of E. coli is known for its plasticity and thus, the ability to evolve constantly. Such genome plasticity enables the strains to survive under different environmental conditions and selective pressures (Dragosits et al., 2013; Laehnemann et al., 2014). Evolution under such conditions may be mediated by mutations, horizontal gene transfer and/or transposable elements. Thus, resistance to a particular antibiotic may be acquired through sequential mutations in the chromosomal DNA or by mobile genomic elements. In the latter case, the exchange of genetic material among bacteria leads to further transmission of resistance (Levy and Marshall, 2004; Barlow, 2009).

In $E$. coli, $\beta$-lactamase mediated resistance is dominated mainly by the acquisition and dissemination of genomic elements through horizontal gene transfer viz. conjugation, transformation and transduction (Doi et al., 2012; Huddleston, 2014). In this regard, it is noteworthy that pathogenic as well as commensal strains of $E$. coli occupy niches which provide ambient conditions for such gene transfer. In the host environments, the population of E. coli is infact more abundant than most other members of Enterobacteriaceae and thus, represents a predominant vehicle for transmission of resistance (O’Brien, 2002; Huddleston, 2014). Even in the natural environments such as urban wastewaters, E. coli strains are surrounded by conditions favorable for exchange of resistance-associated genomic elements, and evolution of newer resistance mechanisms especially in response to subinhibitory concentrations of antibiotics (Rizzo et al., 2013; Wellington et al., 2013). Furthermore, and as discussed in earlier sections, the compounding contribution of the clonal spread of $\beta$-lactamase mediated antibiotic resistance has been most noticeable in the species $E$. coli. The factors contributing to such clonal dissemination, however, need to be investigated in detail.

In view of the diverse and highly efficient means of resistance accumulation and dissemination in E. coli, suitable strategies for tackling drug resistance in this organism are highly warranted. The first step which may be advocated in this direction is the prudent use of currently available antibiotics which in turn requires rapid diagnostics to study susceptibilities in an organism-specific manner. Further, novel antibiotics which attack new target sites or block/circumvent existing resistance mechanisms need to be developed. To accomplish this, knowledge of the detailed mechanisms underlying resistance to particular class of antibiotic in the target organism represents an utmost necessity. The complex nature of mechanisms underlying $\beta$-lactamase mediated resistance in $E$. coli thus, represents a classic example which highlights the need for more such cohesive platforms providing information for other antibiotic-bacteria combinations.

\section{CONCLUDING REMARKS}

The potential of $E$. coli to cause varied infections coupled with having several antibiotic resistance mechanisms is a real challenge to disease management strategies. Of particular concern is the resistance mediated by the newer $\beta$-lactamases since, third-generation cephalosporins and other higher generation $\beta$-lactam antibiotics have long served as the major mainstay for successful treatment of infections caused by E. coli. This review is an attempt to collate key information pertaining to $\beta$-lactamases of significance to $E$. coli. It also highlights the areas of work which needs to be explored 
in future especially, development of rapid diagnostics and understanding association of genotypes with specific resistance types. Studies should also be undertaken to investigate the role of commensal $E$. coli in the global epidemiology of $\beta$-lactamase mediated resistance. The authors suggest that such reviews specifically targeting clinically important pathogens or groups of pathogens would not only serve the clinicians engaged in the management of infections caused by resistant organisms but also provide valuable resource to those interested in designing organism-specific strategies for surveillance and control of resistance in the larger interest of public health.

\section{REFERENCES}

Adler, A., Navon-Venezia, S., Moran-Gilad, J., Marcos, E., Schwartz, D., and Carmeli, Y. (2011). Laboratory and clinical evaluation of screening agar plates for the detection of carbapenem-resistant Enterobacteriaceae from surveillance rectal swabs. J. Clin. Microbiol. 49, 2239-2242. doi: 10.1128/JCM. 02566-10

Afzal-Shah, M., Woodford, N., and Livermore, D. M. (2001). Characterization of OXA-25, OXA-26, and OXA-27, molecular class D $\beta$-lactamases associated with carbapenem resistance in clinical isolates of Acinetobacter baumannii. Antimicrob. Agents Chemother. 45, 583-588. doi: 10.1128/AAC.45.2.583588.2001

Bailar, J. C. III, and Travers, K. (2002). Review of assessments of the human health risk associated with the use of antimicrobial agents in agriculture. Clin. Infect. Dis. 34, S135-S143. doi: 10.1086/340252

Bailey, J. K., Pinyon, J. L., Anantham, S., and Hall, R. M. (2010). Commensal Escherichia coli of healthy humans: a reservoir for antibiotic-resistance determinants. J. Med. Microbiol. 59, 1331-1339. doi: 10.1099/jmm.0.022475-0

Bajaj, P., Kanaujia, P. K., Singh, N. S., Sharma, S., Kumar, S., and Virdi, J. S. (2015). Quinolone co-resistance in ESBL- or AmpC-producing Escherichia coli from an Indian urban aquatic environment and their public health implications. Environ. Sci. Pollut. Res. 23, 1954-1959. doi: 10.1007/s11356-015-5609-x

Baker, K. S. (2015). Demystifying Escherichia coli pathovars. Nat. Rev. Microbiol. 13:5. doi: $10.1038 /$ nrmicro3411

Barlow, M. (2009). What antimicrobial resistance has taught us about horizontal gene transfer. Methods Mol. Biol. 532, 397-411. doi: 10.1007/978-1-60327-8539_23

Barlow, M., and Hall, B. G. (2002). Predicting evolutionary potential: in vitro evolution accurately reproduces natural evolution of the TEM $\beta$-lactamase. Genetics 160, 823-832.

Bartolini, A., Frasson, I., Cavallaro, A., Richter, S. N., and Palù, G. (2014). Comparison of phenotypic methods for the detection of carbapenem nonsusceptible Enterobacteriaceae. Gut Pathog. 6:13. doi: 10.1186/1757-4749-6-13

Bauernfeind, A., Grimm, H., and Schweighart, S. (1990). A new plasmidic cefotaximase in a clinical isolate of Escherichia coli. Infection 18, 294-298. doi: 10.1007/BF01647010

Ben Sallem, R., Ben Slama, K., Sáenz, Y., Rojo-Bezares, B., Estepa, V., Jouini, A., et al. (2012). Prevalence and characterization of extended-spectrum $\beta$-lactamase (ESBL)- and CMY-2-producing Escherichia coli isolates from healthy foodproducing animals in Tunisia. Foodborne. Pathog. Dis. 9, 1137-1142. doi: 10.1089/fpd.2012.1267

Beyrouthy, R., Robin, F., Cougnoux, A., Dalmasso, G., Darfeuille-Michaud, A., Mallat, H., et al. (2013). Chromosome-mediated OXA-48 carbapenemase in highly virulent Escherichia coli. J. Antimicrob. Chemother. 68, 1558-1561. doi: 10.1093/jac/dkt051

Birkett, C. I., Ludlam, H. A., Woodford, N., Brown, D. F., Brown, N. M., Roberts, M. T., et al. (2007). Real-time TaqMan PCR for rapid detection and typing of genes encoding CTX-M extended-spectrum $\beta$-lactamases. J. Med. Microbiol. 56, 52-55. doi: 10.1099/jmm.0.46909-0

Blanco, J., Mora, A., Mamani, R., López, C., Blanco, M., Dahbi, G., et al. (2013). Four main virotypes among extended-spectrum- $\beta$-lactamaseproducing isolates of Escherichia coli O25b:H4-B2-ST131: bacterial,

\section{AUTHOR CONTRIBUTIONS}

$\mathrm{PB}$ reviewed the literature and wrote the manuscript. NS contributed in writing parts of the manuscript. JV conceived the study and checked the manuscript.

\section{ACKNOWLEDGMENT}

PB is thankful to Council of Scientific and Industrial Research (CSIR, New Delhi) for Senior Research Fellowship (09/045 (0965)/2010-EMR-I).

epidemiological, and clinical characteristics. J. Clin. Microbiol. 51, 3358-3367. doi: 10.1128/JCM.01555-13

Bonnet, R. (2004). Growing group of extended-spectrum $\beta$-lactamases: the CTX-M enzymes. Antimicrob. Agents Chemother. 48, 1-14. doi: 10.1128/AAC.48.1.114.2004

Bradford, P. A. (2001). Extended-spectrum $\beta$-lactamases in the 21st century: characterization, epidemiology, and detection of this important resistance threat. Clin. Microbiol. Rev. 14, 933-951. doi: 10.1128/CMR.14.4.933-951.2001

Brenwald, N. P., Jevons, G., Andrews, J., Ang, L., and Fraise, A. P. (2005). Disc methods for detecting AmpC $\beta$-lactamase-producing clinical isolates of Escherichia coli and Klebsiella pneumoniae. J. Antimicrob. Chemother. 56, 600-601. doi: 10.1093/jac/dki278

Brolund, A., Wisell, K. T., Edquist, P. J., Elfström, L., Walder, M., and Giske, C. G. (2010). Development of a real-time SYBRGreen PCR assay for rapid detection of acquired AmpC in Enterobacteriaceae. J. Microbiol. Methods 82, 229-233. doi: 10.1016/j.mimet.2010.06.006

Bui, T. M., Hirai, I., Ueda, S., Bui, T. K., Hamamoto, K., Toyosato, T., et al. (2015). Carriage of Escherichia coli producing CTX-M-Type Extended-Spectrum $\beta$-Lactamase in healthy vietnamese individuals. Antimicrob. Agents Chemother. 59, 6611-6614. doi: 10.1128/AAC.00776-15

Bush, K. (2010). Alarming $\beta$-lactamase-mediated resistance in multidrugresistant Enterobacteriaceae. Curr. Opin. Microbiol. 13, 558-564. doi: 10.1016/j.mib.2010.09.006

Cantón, R., and Coque, T. M. (2006). The CTX-M $\beta$-lactamase pandemic. Curr. Opin. Microbiol. 9, 466-475. doi: 10.1016/j.mib.2006.08.011

Cantón, R., González-Alba, J. M., and Galán, J. C. (2012). CTX-M enzymes: origin and diffusion. Front. Microbiol. 3:110. doi: 10.3389/fmicb.2012.00110

Cantón, R., Morosini, M. I., de la Maza, O. M., and de la Pedrosa, E. G. (2008). IRT and CMT $\beta$-lactamases and inhibitor resistance. Clin. Microbiol. Infect. 14, 53-62. doi: 10.1111/j.1469-0691.2007.01849.x

Cantón, R., and Ruiz-Garbajosa, P. (2011). Co-resistance: an opportunity for the bacteria and resistance genes. Curr. Opin. Pharmacol. 11, 477-485. doi: 10.1016/j.coph.2011.07.007

Carattoli, A. (2013). Plasmids and the spread of resistance. Int. J. Med. Microbiol. 303, 298-304. doi: 10.1016/j.ijmm.2013.02.001

Caroff, N., Espaze, E., Bérard, I., Richet, H., and Reynaud, A. (1999). Mutations in the ampC promoter of Escherichia coli isolates resistant to oxyiminocephalosporins without extended spectrum $\beta$-lactamase production. FEMS Microbiol. Lett. 173, 459-465. doi: 10.1016/S0378-1097(99)00111-1

Carrër, A., Fortineau, N., and Nordmann, P. (2010). Use of ChromID extended-spectrum $\beta$-lactamase medium for detecting carbapenemaseproducing Enterobacteriaceae. J. Clin. Microbiol. 48, 1913-1914. doi: 10.1128/JCM.02277-09

Centers for Disease Control and Prevention (2016). Infectious Diseases Related to Travel, Chap. 3. Available at: http://wwwnc.cdc.gov/travel/yellowbook/2016/in fectious-diseases-related-to-travel/escherichia-coli

Clinical and Laboratory Standards Institute [CLSI] (2014a). Methods for Dilution Antimicrobial Susceptibility Tests for Bacteria That Grow Aerobically; Approved Standard, CLSI document. M07-A9, 9th Edn. Wayne, PA: CLSI.

Clinical and Laboratory Standards Institute [CLSI] (2014b). Performance Standards for Antimicrobial Disk Susceptibility Tests. Approved Standard, 11th Edn. CLSI document M02-A10. Wayne, PA: CLSI. 
Clinical and Laboratory Standards Institute [CLSI] (2014c). Performance Standards for Antimicrobial Susceptibility Testing: Twenty-First Informational Supplement M100-S24. Wayne, PA: CLSI.

Compain, F., Bensekhri, H., Rostane, H., Mainardi, J. L., and Lavollay, M. (2015). $\beta$ LACTA test for rapid detection of Enterobacteriaceae resistant to third-generation cephalosporins from positive blood cultures using briefly incubated solid medium cultures. J. Med. Microbiol. 64, 1256-1259. doi: 10.1099/jmm.0.000157

Coque, T. M., Novais, A., Carattoli, A., Poirel, L., Pitout, J., Peixe, L., et al. (2008). Dissemination of clonally related Escherichia coli strains expressing extended-spectrum $\beta$-lactamase CTX-M-15. Emerg. Infect. Dis. 14, 195-200. doi: $10.3201 /$ eid1402.070350

Corvec, S., Prodhomme, A., Giraudeau, C., Dauvergne, S., Reynaud, A., and Caroff, N. (2007). Most Escherichia coli strains overproducing chromosomal AmpC $\beta$-lactamase belong to phylogenetic group A. J. Antimicrob. Chemother. 60, 872-876. doi: 10.1093/jac/dkm284

Courpon-Claudinon, A., Lefort, A., Panhard, X., Clermont, O., Dornic, Q., Fantin, B., et al. (2011). Bacteraemia caused by third-generation cephalosporinresistant Escherichia coli in France: prevalence, molecular epidemiology and clinical features. Clin. Microbiol. Infect. 17, 557-565. doi: 10.1111/j.14690691.2010.03298.x

Croxen, M. A., Law, R. J., Scholz, R., Keeney, K. M., Wlodarska, M., and Finlay, B. B. (2013). Recent advances in understanding enteric pathogenic Escherichia coli. Clin. Microbiol. Rev. 26, 822-880. doi: 10.1128/CMR.00022-13

Cuzon, G., Naas, T., Bogaerts, P., Glupczynski, Y., and Nordmann, P. (2012). Evaluation of a DNA microarray for the rapid detection of extended-spectrum $\beta$-lactamases (TEM, SHV and CTX-M), plasmid-mediated cephalosporinases (CMY-2-like, DHA, FOX, ACC-1, ACT/MIR and CMY-1-like/MOX) and carbapenemases (KPC, OXA-48, VIM, IMP and NDM). J. Antimicrob. Chemother. 67, 1865-1869. doi: 10.1093/jac/dks156

D’Andrea, M. M., Arena, F., Pallecchi, L., and Rossolini, G. M. (2013). CTX-M-type $\beta$-lactamases: a successful story of antibiotic resistance. Int. J. Med. Microbiol. 303, 305-317. doi: 10.1016/j.ijmm.2013.02.008

Davis, M. A., Sischo, W. M., Jones, L. P., Moore, D. A., Ahmed, S., Short, D. M., et al. (2015). Recent emergence of Escherichia coli with cephalosporin resistance conferred by blaCTX-M on washington state dairy farms. Appl. Environ. Microbiol. 8, 4403-4410. doi: 10.1128/AEM. 00463-15

Day, M. J., Rodríguez, I., van Essen-Zandbergen, A., Dierikx, C., Kadlec, K., Schink, A. K., et al. (2016). Diversity of STs, plasmids and ESBL genes among Escherichia coli from humans, animals and food in Germany, the Netherlands and the UK. J. Antimicrob. Chemother. doi: 10.1093/jac/dkv485 [Epub ahead of print].

Deccache, Y., Irenge, L. M., Ambroise, J., Savov, E., Marinescu, D., Chirimwami, R. B., et al. (2015). A qPCR and multiplex pyrosequencingassay combined with automated data processing for rapid and unambiguous detection of ESBL-producers Enterobacteriaceae. AMB Express 5:136. doi: 10.1186/s13568015-0136-1

Doi, Y., Adams-Haduch, J. M., Peleg, A. Y., and D’Agata, E. M. (2012). The role of horizontal gene transfer in the dissemination of extendedspectrum beta-lactamase-producing Escherichia coli and Klebsiella pneumoniae isolates in an endemic setting. Diagn. Microbiol. Infect. Dis. 74, 34-38. doi: 10.1016/j.diagmicrobio.2012.05.020

Dortet, L., Poirel, L., and Nordmann, P. (2015). Rapid detection of ESBL-producing Enterobacteriaceae in blood cultures. Emerg. Infect. Dis. 21, 504-507. doi: 10.3201/eid2103.141277

Dragosits, M., Mozhayskiy, V., Quinones-Soto, S., Park, J., and Tagkopoulos, I. (2013). Evolutionary potential, cross-stress behavior and the genetic basis of acquired stress resistance in Escherichia coli. Mol. Syst. Biol. 9:643. doi: $10.1038 / \mathrm{msb} .2012 .76$

Drieux, L., Brossier, F., Sougakoff, W., and Jarlier, V. (2008). Phenotypic detection of extended-spectrum $\beta$-lactamase production in Enterobacteriaceae: review and bench guide. Clin. Microbiol. Infect. 14, 90-103. doi: 10.1111/j.14690691.2007.01846.x

Dunne, W. M. Jr., and Hardin, D. J. (2005). Use of several inducer and substrate antibiotic combinations in a disk approximation assay format to screen for AmpC induction in patient isolates of Pseudomonas aeruginosa, Enterobacter spp., Citrobacter spp., and Serratia spp. J. Clin. Microbiol. 43, 5945-5949. doi: 10.1128/JCM.43.12.5945-5949.2005
Dureja, C., Mahajan, S., and Raychaudhuri, S. (2014). Phylogenetic distribution and prevalence of genes encoding class I Integrons and CTX-M-15 extendedspectrum $\beta$-lactamases in Escherichia coli isolates from healthy humans in Chandigarh, India. PLoS ONE 9:e112551. doi: 10.1371/journal.pone.0112551

Eckert, C., Gautier, V., and Arlet, G. (2006). DNA sequence analysis of the genetic environment of various blaCTX-M genes. J. Antimicrob. Chemother. 57, 14-23. doi: $10.1093 /$ jac/dki398

European Committee on Antimicrobial Susceptibility Testing [EUCAST]. (2014). Breakpoint tables for interpretation of MICs and zone diameters, version 4.0. Available at: http://www.eucast.org/clinical_breakpoints. (accessed November 25, 2014)

Ewers, C., Bethe, A., Semmler, T., Guenther, S., and Wieler, L. H. (2012). Extendedspectrum $\beta$-lactamase-producing and AmpC-producing Escherichia coli from livestock and companion animals, and their putative impact on public health: a global perspective. Clin. Microbiol. Infect. 18, 646-655. doi: 10.1111/j.14690691.2012.03850.x

Fortinia, D., Fashaeb, K., Villaa, L., Feudia, C., García-Fernándeza, A., and Carattoli, A. (2015). A novel plasmid carrying blaCTX-M-15 identified in commensal Escherichia coli from healthy pregnant women in Ibadan, Nigeria. J. Glob. Antimicrob. Resist. 3, 9-12. doi: 10.1016/j.jgar.2014.12.002

Franklin, C., Liolios, L., and Peleg, A. Y. (2006). Phenotypic detection of carbapenem-susceptible metallo- $\beta$-lactamase-producing gram-negative bacilli in the clinical laboratory. J. Clin. Microbiol. 44, 3139-3144. doi: 10.1128/JCM.00879-06

Franz, E., Veenman, C., van Hoek, A. H. A. M., Husman, A. R., and Blaak, H. (2015). Pathogenic Escherichia coli producing Extended-spectrum $\beta$-lactamases isolated from surface water and wastewater. Sci. Rep. Nat. 5:14372. doi: $10.1038 /$ srep 14372

Freeman, J. T., Williamson, D. A., Heffernan, H., Smith, M., Bower, J. E., and Roberts, S. A. (2012). Comparative epidemiology of CTX-M-14 and CTX-M-15 producing Escherichia coli: association with distinct demographic groups in the community in New Zealand. Eur. J. Clin. Microbiol. Infect. Dis. 31, 2057-2060. doi: 10.1007/s10096-011-1540-3

García, A., Navarro, F., Miró, E., Mirelis, B., Campoy, S., and Coll, P. (2005). Characterization of the highly variable region surrounding the blaCTX-M-9 gene in non-related Escherichia coli from Barcelona. J. Antimicrob. Chemother. 56, 819-826. doi: 10.1093/jac/dki345

Gazin, M., Paasch, F., Goossens, H., Malhotra-Kumar, S., and Mosar WP2 and Saturn WP1 Study Teams. (2012). Current trends in culture-based and molecular detection of extended-spectrum- $\beta$-lactamase-harboring and carbapenem-resistant Enterobacteriaceae. J. Clin. Microbiol. 50, 1140-1146. doi: 10.1128/JCM.06852-11

Geser, N., Stephan, R., Korczak, B. M., Beutin, L., and Hächler, H. (2012). Molecular identification of extended-spectrum- $\beta$-lactamase genes from Enterobacteriaceae isolated from healthy human carriers in Switzerland. Antimicrob. Agents Chemother. 56, 1609-1612. doi: 10.1128/AAC.05539-11

Giske, C. G., Gezelius, L., Samuelsen, Ø., Warner, M., Sundsfjord, A., and Woodford, N. (2011). A sensitive and specific phenotypic assay for detection of metallo- $\beta$-lactamases and KPC in Klebsiella pneumoniae with the use of meropenem disks supplemented with aminophenylboronic acid, dipicolinic acid and cloxacillin. Clin. Microbiol. Infect. 17, 552-556. doi: 10.1111/j.14690691.2010.03294.x

Glupczynski, Y., Huang, T. D., Bouchahrouf, W., Rezende de Castro, R., Bauraing, C., Gérard, M., et al. (2012). Rapid emergence and spread of OXA-48-producing carbapenem-resistant Enterobacteriaceae isolates in Belgian hospitals. Int. J. Antimicrob. Agents 39, 168-172. doi: 10.1016/j.ijantimicag.2011.10.005

Haenni, M., Châtre, P., and Madec, J. Y. (2014). Emergence of Escherichia coli producing extended-spectrum AmpC $\beta$-lactamases (ESAC) in animals. Front. Microbiol. 5:53. doi: 10.3389/fmicb.2014.00053

Halstead, F. D., Vanstone, G. L., and Balakrishnan, I. (2012). An evaluation of the mast D69C AmpC detection disc set for the detection of inducible and derepressed AmpC $\beta$-lactamases. J. Antimicrob. Chemother. 67, 2303-2304. doi: $10.1093 / \mathrm{jac} / \mathrm{dks} 170$

Hammerum, A. M., Lester, C. H., Jakobsen, L., and Porsbo, L. J. (2011). Faecal carriage of extended-spectrum $\beta$-lactamase-producing and AmpC $\beta$-lactamaseproducing bacteria among Danish army recruits. Clin. Microbiol. Infect. 17, 566-568. doi: 10.1111/j.1469-0691.2010.03340.x 
Hansen, F., Olsen, S. S., Heltberg, O., Justesen, U. S., Fuglsang-Damgaard, D., Knudsen, J. D., et al. (2014). Characterization of third-generation cephalosporin-resistant Escherichia coli from bloodstream infections in Denmark. Microb. Drug Resist. 20, 316-324. doi: 10.1089/mdr.2013.0157

Hanson, N. D., and Sanders, C. C. (1999). Regulation of inducible AmpC $\beta$-lactamase expression among Enterobacteriaceae. Curr. Pharm. Des. 5, 881-894.

Hart, P. J., Wey, E., McHugh, T. D., Balakrishnan, I., and Belgacem, O. (2015). A method for the detection of antibiotic resistance markers in clinical strains of Escherichia coli using MALDI mass spectrometry. J. Microbiol. Methods 111, 1-8. doi: 10.1016/j.mimet.2015.01.020

Hawkey, P. M., and Jones, A. M. (2009). The changing epidemiology of resistance. J. Antimicrob. Chemother. 64, I3-I10. doi: 10.1093/jac/dkp256

Helmy, M., and Wasfi, R. (2014). Phenotypic and molecular characterization of plasmid mediated AmpC ??-lactamases among Escherichia coli, Klebsiella spp., and Proteus mirabilis isolated from urinary tract infections in Egyptian hospitals. BioMed. Res. Int. 2014:171548. doi: 10.1155/2014/171548

Hentschke, M., Kotsakis, S. D., Wolters, M., Heisig, P., Miriagou, V., and Aepfelbacher, M. (2011). CMY-42, a novel plasmid-mediated CMY2 variant AmpC $\beta$-lactamase. Microb. Drug Resist. 17, 165-169. doi: 10.1089/mdr.2010.0137

Honoré, N., Nicolas, M. H., and Cole, S. T. (1986). Inducible cephalosporinase production in clinical isolates of Enterobacter cloacae is controlled by a regulatory gene that has been deleted from Escherichia coli. EMBO J. 5, 3709-3714.

Hordijk, J., Schoormans, A., Kwakernaak, M., Duim, B., Broens, E., Dierikx, C., et al. (2013). High prevalence of fecal carriage of extended spectrum $\beta$-lactamase/AmpC-producing Enterobacteriaceae in cats and dogs. Front. Microbiol. 4:242. doi: 10.3389/fmicb.2013.00242

Hrabák, J., Studentová, V., Walková, R., Zemlicková, H., Jakubu, V., Chudácková, E., et al. (2012). Detection of NDM-1, VIM-1, KPC, OXA-48, and OXA-162 carbapenemases by matrix-assisted laser desorption ionization-time of flight mass spectrometry. J. Clin. Microbiol. 50, 2441-2443. doi: 10.1128/JCM.0100212

Huddleston, J. R. (2014). Horizontal gene transfer in the human gastrointestinal tract: potential spread of antibiotic resistance genes. Infect. Drug Resist. 7, 167-176. doi: 10.2147/IDR.S48820

Izdebski, R., Baraniak, A., Fiett, J., Adler, A., Kazma, M., Salomon, J., et al. (2013). Clonal structure, extended-spectrum $\beta$-lactamases, and acquired AmpCtype cephalosporinases of Escherichia coli populations colonizing patients in rehabilitation centers in four countries. Antimicrob. Agents Chemother. 57, 309-316. doi: 10.1128/AAC.01656-12

Jacoby, G. A. (2009). AmpC $\beta$-lactamases. Clin. Microbiol. Rev. 22, 161-182. doi: 10.1128/CMR.00036-08

Jacoby, G. A., Medeiros, A. A., O’Brien, T. F., Pinto, M. E., and Jiang, H. (1988). Broad-spectrum, transmissible $\beta$-lactamases. N. Engl. J. Med. 319, 723-724. doi: 10.1056/NEJM198809153191114

Jacquier, H., Birgy, A., Le Nagard, H., Mechulam, Y., Schmitt, E., Glodt, J., et al. (2013). Capturing the mutational landscape of the $\beta$-lactamase TEM-1. Proc. Natl. Acad. Sci. U.S.A. 110, 13067-13072. doi: 10.1073/pnas.1215206110

Jarlier, V., Nicolas, M. H., Fournier, G., and Philippon, A. (1988). Extended broad-spectrum beta-lactamases conferring transferable resistance to newer beta-lactam agents in Enterobacteriaceae: hospital prevalence and susceptibility patterns. Rev. Infect. Dis. 10, 867-878. doi: 10.1093/clinids/10.4.867

Jaurin, B., Grundström, T., Edlund, T., and Normark, S. (1981). The E. coli betalactamase attenuator mediates growth rate-dependent regulation. Nature 290, 221-225. doi: 10.1038/290221a0

Jaurin, B., and Normark, S. (1983). Insertion of IS2 creates a novel ampC promoter in Escherichia coli. Cell 32, 809-816. doi: 10.1016/0092-8674(83)90067-3

Jensen, L. B., Hasman, H., Agersø, Y., Emborg, H. D., and Aarestrup, F. M. (2006). First description of an oxyimino-cephalosporin-resistant, ESBLcarrying Escherichia coli isolated from meat sold in Denmark. J. Antimicrob. Chemother. 57, 793-794. doi: 10.1093/jac/dkl048

Johnson, J. R., Johnston, B., Clabots, C., Kuskowski, M. A., and Castanheira, M. (2010). Escherichia coli sequence type ST131 as the major cause of serious multidrug-resistant E. coli infections in the United States. Clin. Infect. Dis. 51, 286-294. doi: 10.1086/653932
Johnson, J. R., Menard, M., Johnston, B., Kuskowski, M. A., Nichol, K., and Zhanel, G. G. (2009). Epidemic clonal groups of Escherichia coli as a cause of antimicrobial-resistant urinary tract infections in Canada, 2002 to 2004. Antimicrob. Agents Chemother. 53, 2733-2739. doi: 10.1128/AAC. 00297-09

Kaneko, K., Sato, Y., Tokunaga, S. K., Tamaki, S. K., Okamoto, R., and Inoue, M. (2006). AmpC $\beta$-lactamase-mediated cefpodoxime-resistant Escherichia coli isolated from faecal samples of healthy volunteers. J. Antimicrob. Chemother. 57, 369-371. doi: 10.1093/jac/dki438

Kaper, J. B., Nataro, J. P., and Mobley, H. L. (2004). Pathogenic Escherichia coli. Nat. Rev. Microbiol. 2, 123-140. doi: 10.1038/nrmicro818

Kothari, C., Gaind, R., Singh, L. C., Sinha, A., Kumari, V., Arya, S., et al. (2013). Community acquisition of $\beta$-lactamase producing Enterobacteriaceae in neonatal gut. BMC Microbiol. 13:136. doi: 10.1186/1471-2180-13-136

Kotsakis, S. D., Caselli, E., Tzouvelekis, L. S., Petinaki, E., Prati, F., and Miriagou, V. (2013). Interactions of oximino-substituted boronic acids and $\beta$-lactams with the CMY-2-derived extended-spectrum cephalosporinases CMY-30 and CMY-42. Antimicrob. Agents Chemother. 57, 968-976. doi: 10.1128/AAC. 01620-12

Kumarasamy, K. K., Toleman, M. A., Walsh, T. R., Bagaria, J., Butt, F., Balakrishnan, R., et al. (2010). Emergence of a new antibiotic resistance mechanism in India, Pakistan, and the UK: a molecular, biological, and epidemiological study. Lancet Infect. Dis. 10, 597-602. doi: 10.1016/S14733099(10)70143-2

Laehnemann, D., Peña-Miller, R., Rosenstiel, P., Beardmore, R., Jansen, G., and Schulenburg, H. (2014). Genomics of rapid adaptation to antibiotics: convergent evolution and scalable sequence amplification. Genome Biol. Evol. 6, 1287-1301. doi: 10.1093/gbe/evu106

Larson, E. (2007). Community factors in the development of antibiotic resistance. Annu. Rev. Public Health 28, 435-447. doi: 10.1146/annurev.publhealth.28.021406.144020

Lasserre, C., De Saint Martin, L., Cuzon, G., Bogaerts, P., Lamar, E., and Glupczynski, Y. (2015). Efficient detection of carbapenemase activity in Enterobacteriaceae by matrix-assisted laser desorption ionization-time of flight mass spectrometry in less than 30 minutes. J. Clin. Microbiol. 53, 2163-2171. doi: 10.1128/JCM.03467-14

Levy, S. B., and Marshall, B. (2004). Antibacterial resistance worldwide: causes, challenges and responses. Nat. Med. 10, S122-S129. doi: 10.1038/nm1145

Li, B., Zhao, Z. C., Wang, M. H., Huang, X. H., Pan, Y. H., and Cao, Y. P. (2014). Antimicrobial resistance and integrons of commensal Escherichia coli strains from healthy humans in China. J. Chemother. 26, 190-192. doi: 10.1179/1973947813Y.0000000113

Li, M., Conklin, B. C., Taracila, M. A., Hutton, R. A., and Skalweit, M. J. (2012). Substitutions at position 105 in SHV family $\beta$-lactamases decrease catalytic efficiency and cause inhibitor resistance. Antimicrob. Agents Chemother. 56, 5678-5686. doi: 10.1128/AAC.00711-12

Liao, X. P., Xia, J., Yang, L., Li, L., Sun, J., Liu, Y. H., et al. (2015). Characterization of CTX-M-14-producing Escherichia coli from food-producing animals. Front. Microbiol. 4:1136. doi: 10.3389/fmicb.2015.01136

Livermore, D. M. (2009). Has the era of untreatable infections arrived? J. Antimicrob. Chemother. Suppl. 1, I29-I36. doi: 10.1093/jac/dkp255

López-Cerero, L., Egea, P., Serrano, L., Navarro, D., Mora, A., Blanco, J., et al. (2011). Characterisation of clinical and food animal Escherichia coli isolates producing CTX-M-15 extended-spectrum $\beta$-lactamase belonging to ST410 phylogroup A. Int. J. Antimicrob. Agents 37, 365-367. doi: 10.1016/j.ijantimicag.2011.01.001

Lutgring, J. D., and Limbago, B. M. (2016). The problem of carbapenemase producing carbapenem-resistant Enterobacteriaceae detection. J. Clin. Microbiol. 54, 529-534. doi: 10.1128/JCM.02771-15

Luvsansharav, U. O., Hirai, I., Nakata, A., Imura, K., Yamauchi, K., Niki, M., et al. (2012). Prevalence of and risk factors associated with faecal carriage of CTX-M $\beta$-lactamase-producing Enterobacteriaceae in rural Thai communities. J. Antimicrob. Chemother. 67, 1769-1774. doi: 10.1093/jac/dks118

Luvsansharav, U. O., Hirai, I., Niki, M., Sasaki, T., Makimoto, K., Komalamisra, C., et al. (2011). Analysis of risk factors for a high prevalence of extended-spectrum $\beta$-lactamase-producing Enterobacteriaceae in asymptomatic individuals in rural Thailand. J. Med. Microbiol. 60, 619-624. doi: 10.1099/jmm.0.026955-0 
Machado, E., Coque, T. M., Cantón, R., Sousa, J. C., and Peixe, L. (2013). Commensal Enterobacteriaceae as reservoirs of extended-spectrum betalactamases, integrons, and sul genes in Portugal. Front. Microbiol. 4:80. doi: 10.3389/fmicb.2013.00080

Majowicz, S. E., Scallan, E., Jones-Bitton, A., Sargeant, J. M., Stapleton, J., and Angulo, F. J. (2014). Global incidence of human Shiga toxin-producing Escherichia coli infections and deaths: a systematic review and knowledge synthesis. Foodborne Pathog. Dis. 11, 447-455. doi: 10.1089/fpd.2013.1704

Manageiro, V., Ferreira, E., Albuquerque, L., Bonnet, R., and Caniça, M. (2010). Biochemical study of a new inhibitor-resistant $\beta$-lactamase, SHV-84, produced by a clinical Escherichia coli strain. Antimicrob. Agents Chemother. 54, 22712272. doi: 10.1128/AAC.01442-09

Matsumura, Y., Nagao, M., Iguchi, M., Yagi, T., Komori, T., Fujita, N., et al. (2013). Molecular and clinical characterization of plasmid-mediated AmpC $\beta$-lactamase-producing Escherichia coli bacteraemia: a comparison with extended-spectrum $\beta$-lactamase-producing and non-resistant $E$. coli bacteraemia. Clin. Microbiol. Infect. 19, 161-168. doi: 10.1111/j.14690691.2012.03762.x

Miriagou, V., Cornaglia, G., Edelstein, M., Galani, I., Giske, C. G., Gniadkowski, M., et al. (2010). Acquired carbapenemases in gram-negative bacterial pathogens: detection and surveillance issues. Clin. Microbiol. Infect. 16, 112-122. doi: 10.1111/j.1469-0691.2009.03116.x

Miriagou, V., Tzouvelekis, L. S., Villa, L., Lebessi, E., Vatopoulos, A. C., Carattoli, A., et al. (2004). CMY-13, a novel inducible cephalosporinase encoded by an Escherichia coli plasmid. Antimicrob. Agents Chemother. 48, 3172-3174. doi: 10.1128/AAC.48.8.3172-3174.2004

Moellering, R. C. Jr. (2010). NDM-1 - a cause for worldwide concern. N. Engl. J. Med. 363, 2377-2379. doi: 10.1056/NEJMp1011715

Mora, A., Blanco, M., López, C., Mamani, R., Blanco, J. E., Alonso, M. P., et al. (2011). Emergence of clonal groups O1:HNM-D-ST59, O15:H1D-ST393, O20:H34/HNM-D-ST354, O25b:H4-B2-ST131 and ONT:H21,42B1-ST101 among CTX-M-14-producing Escherichia coli clinical isolates in Galicia, northwest Spain. Int. J. Antimicrob. Agents 37, 16-21. doi: 10.1016/j.ijantimicag.2010.09.012

Morris, D., McGarry, E., Cotter, M., Passet, V., Lynch, M., Ludden, C., et al. (2012). Detection of OXA-48 carbapenemase in the pandemic clone Escherichia coli O25b:H4-ST131 in the course of investigation of an outbreak of OXA48-producing Klebsiella pneumoniae. Antimicrob. Agents Chemother. 56, 40304031. doi: 10.1128/AAC.00638-12

Mshana, S. E., Imirzalioglu, C., Hain, T., Domann, E., Lyamuya, E. F., and Chakraborty, T. (2011). Multiple ST clonal complexes, with a predominance of ST131, of Escherichia coli harbouring blaCTX-M-15 in a tertiary hospital in Tanzania. Clin. Microbiol. Infect. 17, 1279-1282. doi: 10.1111/j.14690691.2011.03518.x

Munday, C. J., Boyd, D. A., Brenwald, N., Miller, M., Andrews, J. M., Wise, R., et al. (2004). Molecular and kinetic comparison of the novel extended-spectrum $\beta$-lactamases CTX-M-25 and CTX-M-26. Antimicrob. Agents Chemother. 48, 4829-4834. doi: 10.1128/AAC.48.12.4829-4834.2004

Munier, G. K., Johnson, C. L., Snyder, J. W., Moland, E. S., Hanson, N. D., and Thomson, K. S. (2010). Positive extended-spectrum- $\beta$-lactamase (ESBL) screening results may be due to AmpC $\beta$-lactamases more often than to ESBLs. J. Clin. Microbiol. 48, 673-674. doi: 10.1128/JCM.01544-09

Mushtaq, S., Irfan, S., Sarma, J. B., Doumith, M., Pike, R., Pitout, J., et al. (2011). Phylogenetic diversity of Escherichia coli strains producing NDM-type carbapenemases. J. Antimicrob. Chemother. 66, 2002-2005. doi: $10.1093 / \mathrm{jac} / \mathrm{dkr} 226$

Nakayama, T., Ueda, S., Huong, B. T. M., Tuyen, L. D., Komalamisra, C., Kusolsuk, T., et al. (2015). Wide dissemination of extended-spectrum $\beta$-lactamase-producing Escherichia coli in community residents in the Indochinese peninsula. Inf. Drug Res. 8, 1-5. doi: 10.2147/IDR.S74934

Naseer, U., Haldorsen, B., Simonsen, G. S., and Sundsfjord, A. (2010). Sporadic occurrence of CMY-2-producing multidrug-resistant Escherichia coli of STcomplexes 38 and 448, and ST131 in Norway. Clin. Microbiol. Infect. 16, 171-178. doi: 10.1111/j.1469-0691.2009.02861.x

Naseer, U., and Sundsfjord, A. (2011). The CTX-M conundrum: dissemination of plasmids and Escherichia coli clones. Microb. Drug Resist. 17, 83-97. doi: $10.1089 / \mathrm{mdr} .2010 .0132$
Nelson, E. C., and Elisha, B. G. (1999). Molecular basis of AmpC hyperproduction in clinical isolates of Escherichia coli. Antimicrob. Agents Chemother. 43, 957-959.

Nicolas-Chanoine, M. H., Blanco, J., Leflon-Guibout, V., Demarty, R., Alonso, M. P., Caniça, M. M., et al. (2008). Intercontinental emergence of Escherichia coli clone O25:H4-ST131 producing CTX-M-15. J. Antimicrob. Chemother. 61, 273-281. doi: 10.1093/jac/dkm464

Nordmann, P., Cuzon, G., and Naas, T. (2009). The real threat of Klebsiella pneumoniae carbapenemase-producing bacteria. Lancet Infect. Dis. 9, 228-236. doi: 10.1016/S1473-3099(09)70054-4

Nordmann, P., Gniadkowski, M., Giske, C. G., Poirel, L., Woodford, N., Miriagou, V., et al. (2012a). Identification and screening of carbapenemaseproducing Enterobacteriaceae. Clin. Microbiol. Infect. 18, 432-438. doi: 10.1111/j.1469-0691.2012.03815.x

Nordmann, P., Naas, T., and Poirel, L. (2011a). Global spread of Carbapenemaseproducing Enterobacteriaceae. Emerg. Infect. Dis. 17, 1791-1798. doi: 10.3201/eid1710.110655

Nordmann, P., Poirel, L., and Dortet, L. (2012b). Rapid detection of carbapenemase-producing Enterobacteriaceae. Emerg. Infect. Dis. 18, 15031507. doi: 10.3201/eid1809.120355

Nordmann, P., Poirel, L., Toleman, M. A., and Walsh, T. R. (2011b). Does broadspectrum $\beta$-lactam resistance due to NDM-1 herald the end of the antibiotic era for treatment of infections caused by gram-negative bacteria? J. Antimicrob. Chemother. 66, 689-692. doi: 10.1093/jac/dkq520

Nourrisson, C., Tan, R. N., Hennequin, C., Gibold, L., Bonnet, R., and Robin, F. (2015). The MAST D68C test: an interesting tool for detecting extendedspectrum $\beta$-lactamase (ESBL)-producing Enterobacteriaceae. Eur. J. Clin. Microbiol. Infect. Dis. 34, 975-983. doi: 10.1007/s10096-014-2305-6

Novais, A., Cantón, R., Valverde, A., Machado, E., Galán, J. C., Peixe, L., et al. (2006). Dissemination and persistence of blaCTX-M-9 are linked to class 1 integrons containing CR1 associated with defective transposon derivatives from Tn402 located in early antibiotic resistance plasmids of IncHI2, IncP1alpha, and IncFI groups. Antimicrob. Agents Chemother. 50, 2741-2750. doi: 10.1128/AAC.00274-06

Nys, S., Okeke, I. N., Kariuki, S., Dinant, G. J., Driessen, C., and Stobberingh, E. E. (2004). Antibiotic resistance of faecal Escherichia coli from healthy volunteers from eight developing countries. J. Antimicrob. Chemother. 54, 952-955. doi: $10.1093 / \mathrm{jac} / \mathrm{dkh} 448$

O'Brien, T. F. (2002). Emergence, spread, and environmental effect of antimicrobial resistance: how use of an antimicrobial anywhere can increase resistance to any antimicrobial anywhere else. Clin. Infect. Dis. 34, S78-S84. doi: $10.1086 / 340244$

Oliver, A., Coque, T. M., Alonso, D., Valverde, A., Baquero, F., and Cantón, R. (2005). CTX-M-10 linked to a phage-related element is widely disseminated among Enterobacteriaceae in a Spanish hospital. Antimicrob. Agents Chemother. 49, 1567-1571. doi: 10.1128/AAC.49.4.1567-1571.2005

Ortega, A., Oteo, J., Aranzamendi-Zaldumbide, M., Bartolomé, R. M., Bou, G., Cercenado, E., et al. (2012). Spanish multicenter study of the epidemiology and mechanisms of amoxicillin-clavulanate resistance in Escherichia coli. Antimicrob. Agents Chemother. 56, 3576-3581. doi: 10.1128/AAC.06393-11

Oteo, J., Cercenado, E., Cuevas, O., Bautista, V., Delgado-Iribarren, A., Orden, B., et al. (2010). AmpC $\beta$-lactamases in Escherichia coli: emergence of CMY2-producing virulent phylogroup D isolates belonging mainly to STs 57, $115,354,393$, and 420, and phylogroup B2 isolates belonging to the international clone O25b-ST131. Diagn. Microbiol. Infect. Dis. 67, 270-276. doi: 10.1016/j.diagmicrobio.2010.02.008

Oteo, J., Diestra, K., Juan, C., Bautista, V., Novais, A., Pérez-Vázquez, M., et al. (2009). Extended-spectrum $\beta$-lactamase-producing Escherichia coli in Spain belong to a large variety of multilocus sequence typing types, including ST10 complex/A, ST23 complex/A, and ST131/B2. Int. J. Antimicrob. Agents 34, 173-176. doi: 10.1016/j.ijantimicag.2009.03.006

Oteo, J., González-López, J. J., Ortega, A., Quintero-Zárate, J. N., Bou, G., Cercenado, E., et al. (2014). Inhibitor-resistant TEM- and OXA-1-producing Escherichia coli isolates resistant to amoxicillin-clavulanate are more clonal and possess lower virulence gene content than susceptible clinical isolates. Antimicrob. Agents Chemother. 58, 3874-3881. doi: 10.1128/AAC. 02738-13 
Pallecchi, L., Bartoloni, A., Fiorelli, C., Mantella, A., Di Maggio, T., Gamboa, H., et al. (2007). Rapid dissemination and diversity of CTX-M extended-spectrum $\beta$-lactamase genes in commensal Escherichia coli isolates from healthy children from low-resource settings in Latin America. Antimicrob. Agents Chemother. 51, 2720-2725. doi: 10.1128/AAC.00026-07

Paterson, D. L., and Bonomo, R. A. (2005). Extended-spectrum beta-lactamases: a clinical update. Clin. Microbiol. Rev. 18, 657-686. doi: 10.1128/CMR.18.4.657686.2005

Peirano, G., Bradford, P. A., Kazmierczak, K. M., Badal, R. E., Hackel, M., Hoban, D. J., et al. (2014a). Global incidence of carbapenemase-producing Escherichia coli ST131. Emerg. Infect. Dis. 20, 1928-1931. doi: 10.3201/eid2011. 141388

Peirano, G., Schreckenberger, P. C., and Pitout, J. D. (2011). Characteristics of NDM-1-producing Escherichia coli isolates that belong to the successful and virulent clone ST131. Antimicrob. Agents Chemother. 55, 2986-2988. doi: 10.1128/AAC.01763-10

Peirano, G., van der Bij, A. K., Freeman, J. L., Poirel, L., Nordmann, P., Costello, M., et al. (2014b). Characteristics of Escherichia coli sequence type 131 isolates that produce extended-spectrum $\beta$-lactamases: global distribution of the H30-Rx sublineage. Antimicrob. Agents Chemother. 58, 3762-3767. doi: 10.1128/AAC.02428-14

Pérez-Pérez, F. J., and Hanson, N. D. (2002). Detection of plasmid-mediated AmpC $\beta$-lactamase genes in clinical isolates by using multiplex PCR. J. Clin. Microbiol. 40, 2153-2162. doi: 10.1128/JCM.40.6.2153-2162.2002

Peter-Getzlaff, S., Polsfuss, S., Poledica, M., Hombach, M., Giger, J., Böttger, E. C., et al. (2011). Detection of AmpC $\beta$-lactamase in Escherichia coli: comparison of three phenotypic confirmation assays and genetic analysis. J. Clin. Microbiol. 49, 2924-2932. doi: 10.1128/JCM.00091-11

Pfeifer, Y., Cullik, A., and Witte, W. (2010). Resistance to cephalosporins and carbapenems in gram-negative bacterial pathogens. Int. J. Med. Microbiol. 300, 371-379. doi: 10.1016/j.ijmm.2010.04.005

Pfeifer, Y., Witte, W., Holfelder, M., Busch, J., Nordmann, P., and Poirel, L. (2011). NDM-1-producing Escherichia coli in Germany. Antimicrob. Agents Chemother. 55, 1318-1319. doi: 10.1128/AAC.01585-10

Phan, M. D., Forde, B. M., Peters, K. M., Sarkar, S., Hancock, S., StantonCook, M., et al. (2015). Molecular characterization of a multidrug resistance IncF plasmid from the globally disseminated Escherichia coli ST131 clone. PLoS ONE 10:e0122369. doi: 10.1371/journal.pone.0122369

Philippon, A., Arlet, G., and Jacoby, G. A. (2002). Plasmid-determined AmpC-type $\beta$-lactamases. Antimicrob. Agents Chemother. 46, 1-11. doi: 10.1128/AAC.46.1.1-11.2002

Philippon, A., Labia, R., and Jacoby, G. (1989). Extended-spectrum $\beta$-lactamases. Antimicrob. Agents Chemother. 33, 1131-1136. doi: 10.1128/AAC.33. 8.1131

Pitout, J. D. (2010). Infections with extended-spectrum $\beta$-lactamase-producing Enterobacteriaceae: changing epidemiology and drug treatment choices. Drugs 70, 313-333. doi: 10.2165/11533040-000000000-00000

Poirel, L., Kieffera, N., Liassine, N., Thanh, D., and Nordmann, P. (2016). Plasmidmediated carbapenem and colistin resistance in a clinical isolate of Escherichia coli. Lancet Infect. Dis.16:281. doi: 10.1016/S1473-3099(16)00006-2

Poirel, L., Lagrutta, E., Taylor, P., Pham, J., and Nordmann, P. (2010). Emergence of metallo- $\beta$-lactamase NDM-1-producing multidrug-resistant Escherichia coli in Australia. Antimicrob. Agents Chemother. 54, 4914-4916. doi: 10.1128/AAC.00878-10

Poirel, L., Lartigue, M. F., Decousser, J. W., and Nordmann, P. (2005). ISEcp1Bmediated transposition of blaCTX-M in Escherichia coli. Antimicrob. Agents Chemother. 49, 447-450. doi: 10.1128/AAC.49.1.447-450.2005

Poirel, L., Naas, T., Le Thomas, I., Karim, A., Bingen, E., and Nordmann, P. (2001). CTX-M-type extended-spectrum beta-lactamase that hydrolyzes ceftazidime through a single amino acid substitution in the omega loop. Antimicrob. Agents Chemother. 45, 3355-3361. doi: 10.1128/AAC.45.12.3355-3361.2001

Poirel, L., Walsh, T. R., Cuvillier, V., and Nordmann, P. (2011). Multiplex PCR for detection of acquired carbapenemase genes. Diagn. Microbiol. Infect. Dis. 70, 119-123. doi: 10.1016/j.diagmicrobio.2010.12.002

Poolman, J. T., and Wacker, M. (2016). Extraintestinal pathogenic Escherichia coli, a common human pathogen: challenges for vaccine development and progress in the field. J. Infect. Dis. 213, 6-13. doi: 10.1093/infdis/jiv429
Pournaras, S., Poulou, A., Voulgari, E., Vrioni, G., Kristo, I., and Tsakris, A. (2010). Detection of the new metallo-beta-lactamase VIM-19 along with KPC2, CMY-2 and CTX-M-15 in Klebsiella pneumoniae. J. Antimicrob. Chemother. 65, 1604-1607. doi: 10.1093/jac/dkq190

Price, L. B., Johnson, J. R., Aziz, M., Clabots, C., Johnston, B., Tchesnokova, V., et al. (2013). The epidemic of extended-spectrum- $\beta$-lactamase-producing Escherichia coli ST131 is driven by a single highly pathogenic subclone, H30-Rx. MBio 4:e377-13. doi: 10.1128/mBio.00377-13

Prinarakis, E. E., Miriagou, V., Tzelepi, E., Gazouli, M., and Tzouvelekis, L. S. (1997). Emergence of an inhibitor-resistant $\beta$-lactamase (SHV-10) derived from an SHV-5 variant. Antimicrob. Agents Chemother. 41, 838-840.

Qadri, F., Svennerholm, A. M., Faruque, A. S., and Sack, R. B. (2005). Enterotoxigenic Escherichia coli in developing countries: epidemiology, microbiology, clinical features, treatment, and prevention. Clin. Microbiol. Rev. 18, 465-483. doi: 10.1128/CMR.18.3.465-483.2005

Queenan, A. M., and Bush, K. (2007). Carbapenemases: the versatile $\beta$-lactamases. Clin. Microbiol. Rev. 20, 440-458. doi: 10.1128/CMR.00001-07

Riley, L. W. (2014). Pandemic lineages of extraintestinal pathogenic Escherichia coli. Clin. Microbiol. Infect. 20, 380-390. doi: 10.1111/1469-0691.12646

Riley, L. W., Remis, R. S., Helgerson, S. D., McGee, H. B., Wells, J. G., Davis, B. R., et al. (1983). Hemorrhagic colitis associated with a rare Escherichia coli serotype. N. Engl. J. Med. 308, 681-685. doi: 10.1056/NEJM198303243081203

Ripoll, A., Baquero, F., Novais, A., Rodríguez-Domínguez, M. J., Turrientes, M. C., Cantón, R., et al. (2011). In vitro selection of variants resistant to $\beta$-lactams plus $\beta$-lactamase inhibitors in CTX-M $\beta$-lactamases: predicting the in vivo scenario? Antimicrob. Agents Chemother. 55, 4530-4536. doi: 10.1128/AAC.00178-11

Ripoll, A., Galán, J. C., Rodríguez, C., Tormo, N., Gimeno, C., Baquero, F., et al. (2014). Detection of resistance to $\beta$-lactamase inhibitors in strains with CTX-M $\beta$-lactamases: a multicenter external proficiency study using a welldefined collection of Escherichia coli strains. J. Clin. Microbiol. 52, 122-129. doi: 10.1128/JCM.02340-13

Rizzo, L., Manaia, C., Merlin, C., Schwartz, T., Dagot, C., Ploy, M. C., et al. (2013). Urban wastewater treatment plants as hotspots for antibiotic resistant bacteria and genes spread into the environment: a review. Sci. Total Environ. 447, 345-360. doi: 10.1016/j.scitotenv.2013.01.032

Robin, F., Krebs, M., Delmas, J., Gibold, L., Mirande, C., and Bonnet, R. (2011). In vitro efficiency of the piperacillin/tazobactam combination against inhibitor-resistant TEM- and complex mutant TEM-producing clinical strains of Escherichia coli. J. Antimicrob. Chemother. 66, 1052-1056. doi: $10.1093 / \mathrm{jac} / \mathrm{dkr} 045$

Rodríguez-Baño, J., López-Cerero, L., Navarro, M. D., Díaz de Alba, P., and Pascual, A. (2008). Faecal carriage of extended-spectrum $\beta$-lactamaseproducing Escherichia coli: prevalence, risk factors and molecular epidemiology. J. Antimicrob. Chemother. 62, 1142-1149. doi: 10.1093/jac/ $\mathrm{dkn} 293$

Rogers, B. A., Sidjabat, H. E., and Paterson, D. L. (2011). Escherichia coli O25bST131: a pandemic, multiresistant, community-associated strain. J. Antimicrob. Chemother. 66, 1-14. doi: 10.1093/jac/dkq415

Ruppé, E., Armand-Lefèvre, L., Estellat, C., El-Mniai, A., Boussadia, Y., Consigny, P. H., et al. (2014). Acquisition of carbapenemase-producing Enterobacteriaceae by healthy travellers to India, France, February 2012 to March 2013. Euro. Surveill. 19:20768. doi: 10.2807/1560-7917.ES2014.19.14.20768

Russo, T. A., and Johnson, J. R. (2003). Medical and economic impact of extraintestinal infections due to Escherichia coli: focus on an increasingly important endemic problem. Microbes Infect. 5, 449-456. doi: 10.1016/S12864579(03)00049-2

Sabaté, M., Navarro, F., Miró, E., Campoy, S., Mirelis, B., Barbé, J., et al. (2002). Novel complex sul1-type integron in Escherichia coli carrying blaCTX-M-9. Antimicrob. Agents Chemother. 46, 2656-2661. doi: 10.1128/AAC.46.8.26562661.2002

Sidjabat, H. E., Paterson, D. L., Qureshi, Z. A., Adams-Haduch, J. M., O’Keefe, A., Pascual, A., et al. (2009). Clinical features and molecular epidemiology of CMYtype $\beta$-lactamase-producing Escherichia coli. Clin. Infect. Dis. 48, 739-744. doi: $10.1086 / 597037$

Silva, K. C., Morenoa, M., Cabreraa, C., Spirab, B., Cerdeirab, L., Lincopanb, N., et al. (2016). First characterization of CTX-M-15-producing Escherichia coli strains belonging to ST410, ST224 and ST1284 from commercial swine in South 
America. Antimicrob. Agents Chemother. doi: 10.1128/AAC.02788-15 [Epub ahead of print].

Smet, A., Martel, A., Persoons, D., Dewulf, J., Heyndrickx, M., Claeys, G., et al. (2010). Characterization of extended-spectrum beta-lactamases produced by Escherichia coli isolated from hospitalized and nonhospitalized patients: emergence of CTX-M-15-producing strains causing urinary tract infections. Microb. Drug Resist. 16, 129-134. doi: 10.1089/mdr.2009.0132

Sommer, M. O., Dantas, G., and Church, G. M. (2009). Functional characterization of the antibiotic resistance reservoir in the human microflora. Science 325, 1128-1131. doi: 10.1126/science. 1176950

Stoesser, N., Batty, E. M., Eyre, D. W., Morgan, M., Wyllie, D. H., Del Ojo Elias, C., et al. (2013). Predicting antimicrobial susceptibilities for Escherichia coli and Klebsiella pneumoniae isolates using whole genomic sequence data. J. Antimicrob. Chemother. 68, 2234-2244. doi: 10.1093/jac/dkt180

Tacão, M., Correia, A., and Henriques, I. (2012). Resistance to broadspectrum antibiotics in aquatic systems: anthropogenic activities modulate the dissemination of blaCTX-M-like genes. Appl. Environ. Microbiol. 78, 4134-4140. doi: 10.1128/AEM.00359-12

Tan, T. Y., Ng, S. Y., Teo, L., Koh, Y., and Teok, C. H. (2008). Detection of plasmid-mediated AmpC in Escherichia coli, Klebsiella pneumoniae and Proteus mirabilis. J. Clin. Pathol. 61, 642-644. doi: 10.1136/jcp.2007.053470

Tängdén, T., Cars, O., Melhus, A., and Löwdin, E. (2010). Foreign travel is a major risk factor for colonization with Escherichia coli producing CTX-M-type extended-spectrum $\beta$-lactamases: a prospective study with Swedish volunteers. Antimicrob. Agents Chemother. 54, 3564-3568. doi: 10.1128/AAC.00220-10

Tenover, F. C., Emery, S. L., Spiegel, C. A., Bradford, P. A., Eells, S., Endimiani, A., et al. (2009). Identification of plasmid-mediated AmpC $\beta$-lactamases in Escherichia coli, Klebsiella spp., and Proteus species can potentially improve reporting of cephalosporin susceptibility testing results. J. Clin. Microbiol. 47, 294-299. doi: 10.1128/JCM.01797-08

Thomson, J. M., Distler, A. M., and Bonomo, R. A. (2007). Overcoming resistance to $\beta$-lactamase inhibitors: comparing sulbactam to novel inhibitors against clavulanate resistant SHV enzymes with substitutions at Ambler position 244. Biochemistry 46, 11361-11368. doi: 10.1021/bi700792a

Thomson, K. S. (2010). Extended-spectrum- $\beta$-lactamase, AmpC, and Carbapenemase issues. J. Clin. Microbiol. 48, 1019-1025. doi: 10.1128/JCM.00219-10

Tian, G. B., Wang, H. N., Zhang, A. Y., Zhang, Y., Fan, W. Q., Xu, C. W., et al. (2012). Detection of clinically important $\beta$-lactamases in commensal Escherichia coli of human and swine origin in western China. J. Med. Microbiol. 61, 233-238. doi: 10.1099/jmm.0.036806-0

Urban, C., Bradford, P. A., Tuckman, M., Segal-Maurer, S., Wehbeh, W., Grenner, L., et al. (2008). Carbapenem-resistant Escherichia coli harboring Klebsiella pneumoniae carbapenemase $\beta$-lactamases associated with long-term care facilities. Clin. Infect. Dis. 46, e127-e130. doi: 10.1086/588048

Valenza, G., Nickel, S., Pfeifer, Y., Eller, C., Krupa, E., Lehner-Reindl, V., et al. (2014). Extended-spectrum- $\beta$-lactamase-producing Escherichia coli as intestinal colonizers in the German community. Antimicrob. Agents Chemother. 58, 1228-1230. doi: 10.1128/AAC.01993-13

Valverde, A., Cantón, R., Garcillán-Barcia, M. P., Novais, A., Galán, J. C., Alvarado, A., et al. (2009). Spread of blaCTX-M-14 is driven mainly by IncK plasmids disseminated among Escherichia coli phylogroups A, B1, and D in Spain. Antimicrob. Agents Chemother. 53, 5204-5212. doi: 10.1128/AAC. 01706-08

Valverde, A., Grill, F., Coque, T. M., Pintado, V., Baquero, F., Cantón, R., et al. (2008). High rate of intestinal colonization with extendedspectrum- $\beta$-lactamase-producing organisms in household contacts of infected community patients. J. Clin. Microbiol. 46, 2796-2799. doi: 10.1128/JCM.01008-08

Valverde, A., Turrientes, M. C., Norman, F., San Martín, E., Moreno, L., PérezMolina, J. A., et al. (2015). CTX-M-15-non-ST131 Escherichia coli isolates are mainly responsible of faecal carriage with ESBL-producing Enterobacteriaceae in travellers, immigrants and those visiting friends and relatives. Clin. Microbiol. Infect. 21, 252.e1-252.e4. doi: 10.1016/j.cmi.2014.09.021

van der Bij, A. K., Peirano, G., Goessens, W. H., van der Vorm, E. R., van Westreenen, M., and Pitout, J. D. (2011). Clinical and molecular characteristics of extended-spectrum- $\beta$-lactamase-producing Escherichia coli causing bacteremia in the Rotterdam Area, Netherlands. Antimicrob. Agents Chemother. 55, 3576-3578. doi: 10.1128/AAC.00074-11

van der Zee, A., Roorda, L., Bosman, G., Fluit, A. C., Hermans, M., Smits, P. H., et al. (2014). Multi-centre evaluation of real-time multiplex PCR for detection of carbapenemase genes OXA-48, VIM, IMP, NDM and KPC. BMC Infect. Dis. 14:27. doi: 10.1186/1471-2334-14-27

Vrioni, G., Daniil, I., Voulgari, E., Ranellou, K., Koumaki, V., Ghirardi, S., et al. (2012). Comparative evaluation of a prototype chromogenic medium (ChromID CARBA) for detecting carbapenemase-producing Enterobacteriaceae in surveillance rectal swabs. J. Clin. Microbiol. 50, 1841-1846. doi: 10.1128/JCM.06848-11

Wellington, E. M., Boxall, A. B., Cross, P., Feil, E. J., Gaze, W. H., Hawkey, P. M., et al. (2013). The role of the natural environment in the emergence of antibiotic resistance in gram-negative bacteria. Lancet Infect. Dis. 13, 155-165. doi: 10.1016/S1473-3099(12)70317-1

Wiegand, I., Geiss, H. K., Mack, D., Stürenburg, E., and Seifert, H. (2007). Detection of extended-spectrum $\beta$-lactamases among Enterobacteriaceae by use of semiautomated microbiology systems and manual detection procedures. J. Clin. Microbiol. 45, 1167-1174. doi: 10.1128/JCM.01988-06

Winkler, M. L., Papp-Wallace, K. M., Taracila, M. A., and Bonomo, R. A. (2015). Avibactam and inhibitor-resistant SHV $\beta$-lactamases. Antimicrob. Agents Chemother. 59, 3700-3709. doi: 10.1128/AAC. 04405-14

Woerther, P. L., Burdet, C., Chachaty, E., and Andremont, A. (2013). Trends in human fecal carriage of extended-spectrum $\beta$-lactamases in the community: toward the globalization of CTX-M. Clin. Microbiol. Rev. 26, 744-758. doi: 10.1128/CMR.00023-13

Woodford, N., Turton, J. F., and Livermore, D. M. (2011). Multiresistant Gram-negative bacteria: the role of high-risk clones in the dissemination of antibiotic resistance. FEMS Microbiol. Rev. 35, 736-755. doi: 10.1111/j.15746976.2011.00268.x

Woodford, N., Ward, M. E., Kaufmann, M. E., Turton, J., Fagan, E. J., James, D., et al. (2004). Community and hospital spread of Escherichia coli producing CTX-M extended-spectrum $\beta$-lactamases in the UK. J. Antimicrob. Chemother. 54, 735-743. doi: 10.1093/jac/dkh424

Zankari, E., Hasman, H., Kaas, R. S., Seyfarth, A. M., Agersø, Y., Lund, O., et al. (2013). Genotyping using whole-genome sequencing is a realistic alternative to surveillance based on phenotypic antimicrobial susceptibility testing. J. Antimicrob. Chemother. 68, 771-777. doi: 10.1093/jac/ dks496

Zheng, H., Zeng, Z., Chen, S., Liu, Y., Yao, Q., Deng, Y., et al. (2012). Prevalence and characterisation of CTX-M $\beta$-lactamases amongst Escherichia coli isolates from healthy food animals in China. Int. J. Antimicrob. Agents 39, 305-310. doi: 10.1016/j.ijantimicag.2011.12.001

Conflict of Interest Statement: The authors declare that the research was conducted in the absence of any commercial or financial relationships that could be construed as a potential conflict of interest.

Copyright (c) 2016 Bajaj, Singh and Virdi. This is an open-access article distributed under the terms of the Creative Commons Attribution License (CC BY). The use, distribution or reproduction in other forums is permitted, provided the original author(s) or licensor are credited and that the original publication in this journal is cited, in accordance with accepted academic practice. No use, distribution or reproduction is permitted which does not comply with these terms. 